\title{
Obstructive Lymphangitis Precedes Colitis in Murine Norovirus-Infected Stat1-Deficient Mice
}

From the Departments of Comparative Medicine* and Microbiology, ${ }^{\S}$ University of Washington, Seattle, Washington; the Department of Molecular and Cellular Physiology, ${ }^{\dagger}$ Louisiana State University, Shreveport, Louisiana; and the Department of Veterinary Pathobiology, ${ }^{\ddagger}$ University of Missouri, Columbia, Missouri

\author{
Accepted for publication \\ March 26, 2018. \\ Address correspondence to \\ Audrey Seamons, Ph.D., \\ Department of Comparative \\ Medicine, University of \\ Washington, Campus Box \\ 357340, 1959 NE Pacific St, \\ Seattle, WA 98195. E-mail: \\ auds@uw.edu.
}

\begin{abstract}
Murine norovirus (MNV) is an RNA virus that can prove lethal in mice with impaired innate immunity. We found that MNV-4 infection of Stat $1^{-/-}$mice was not lethal, but produced a $100 \%$ penetrant, previously undescribed lymphatic phenotype characterized by chronic-active lymphangitis with hepatitis, splenitis, and chronic cecal and colonic inflammation. Lesion pathogenesis progressed from early ileal enteritis and regional dilated lymphatics to lymphangitis, granulomatous changes in the liver and spleen, and, ultimately, typhlocolitis. Lesion development was neither affected by antibiotics nor reproduced by infection with another enteric RNA virus, rotavirus. MNV-4 infection in Stat $1^{-/-}$mice decreased expression of vascular endothelial growth factor (Vegf) receptor 3, Vegf-c, and Vegf-d and increased interferon (Ifn)- $\gamma$, tumor necrosis factor- $\alpha$, and inducible nitric oxide synthase. However, anti-IFN- $\gamma$ and anti-tumor necrosis factor- $\alpha$ antibody treatment did not attenuate the histologic lesions. Studies in Ifn $\alpha \beta \gamma r^{-/-}$mice suggested that canonical signaling via interferon receptors did not cause MNV-4-induced disease. Infected Stat ${ }^{-/-}$mice had increased STAT3 phosphorylation and expressed many STAT3-regulated genes, consistent with our findings of increased myeloid cell subsets and serum granulocyte colony-stimulating factor, which are also associated with increased STAT3 activity. In conclusion, in Stat $1^{-/-}$mice, MNV-4 induces lymphatic lesions similar to those seen in Crohn disease as well as hepatitis, splenitis, and typhlocolitis. MNV-4-infected Stat $1^{-1}$ mice may be a useful model to study mechanistic associations between viral infections, lymphatic dysfunction, and intestinal inflammation in a genetically susceptible host. (Am J Pathol 2018, 188: 1536-1554; https://doi.org/ 10.1016/j.ajpath.2018.03.019)
\end{abstract}

Ulcerative colitis and Crohn disease (CD) are gastrointestinal disorders characterized by chronic and relapsing inflammation. The precise etiology of these inflammatory bowel diseases (IBDs) is unknown, but epidemiologic and animal studies suggest that underlying genetic predispositions in combination with changes in the gut microbiome may initiate and sustain disease. The earliest descriptions of CD suggested an important role for the lymphatic system in $\mathrm{CD}$ pathogenesis. ${ }^{1-3}$ Presently, there is an increasing body of literature supporting the role of dysfunctional lymphatics in the development of IBD, with patients exhibiting granulomatous changes linked with chronic lymphangitis, lymphostasis, accumulation of lymphocytes in lymphatic channels, and extensive remodeling and dilation of lymphatics. ${ }^{4-8}$ Several experimental models of IBD indicate that gut lymphatic function may decrease before the development of intestinal inflammation and contribute to IBD etiopathogenesis. ${ }^{9-11}$

It is widely accepted that gut microbes are altered in IBD, but it is far less clear whether and how specific commensal or pathogenic infectious agents may influence IBD. ${ }^{12,13}$ Although viruses are not clearly linked to IBD, viral triggers for IBD have long been suspected. ${ }^{14}$ A recent survey using deep sequencing techniques identified cytomegalovirus, Epstein-Barr

Supported by NIH grants R01-OD011149 (L.M.-P.) and K01 OD021420 (S.M.), and Department of Defense grant W81XWH-11-1-0577 (J.S.A.)

Disclosures: None declared. 
virus, parvoviruses, and adenoviruses in IBD patients undergoing surgery but not in controls undergoing surveillance colonic biopsies. ${ }^{15}$ Noroviruses have been associated with exacerbation of IBD in human patients. ${ }^{16}$ Given the complexity of the gut microbiome and human hosts, viral involvement in IBD is likely multifactorial; viruses may modulate effects of other microbes, compromise the intestinal epithelial barrier, or modify the overall immune function of the host to contribute to the initiation of and development of IBD. ${ }^{17}$

Noroviruses of the Caliciviridae family are nonenveloped, single-stranded, positive-sense RNA enteric viruses that are important causes of human gastrointestinal disease. ${ }^{18}$ By comparison, murine norovirus (MNV) has neither been shown to cause acute clinical gastrointestinal disease nor chronic bowel inflammation in immunocompetent mouse models. ${ }^{19}$ However, MNV has been associated with morbidity and mortality in mutant mouse strains with deficient innate immunity. ${ }^{20}$ Stat $^{-1-}$ mice have impaired innate immunity, and MNV infection in these mice produces diverse outcomes in survival and lesion development, depending on the route of infection and the strain of MNV used. ${ }^{19}$ Infection with MNV-4, a strain that persistently infects mice, ${ }^{21}$ variably affects disease severity in murine models of colitis, obesity, and atherosclerosis. ${ }^{22-25}$ Herein, in Stat1 $^{-1-}$ mice infected with MNV-4, we describe previously unreported lesions in lymphatics that resemble those described in human CD. ${ }^{1,8,26}$ These lesions were accompanied by the development of mild to moderate chronic typhlocolitis. Our findings may have important relevance to human CD in that aberrant STAT1 signaling is seen in dendritic cells of CD patients, ${ }^{27}$ and STAT polymorphisms have been identified in genome-wide association screens as susceptibility loci. ${ }^{28}$ In addition, recent studies provide compelling evidence for a previously uncharacterized role of the intestinal virome in both $\mathrm{CD}$ and ulcerative colitis. ${ }^{15,29}$ This model may be useful for understanding cooperative interactions between intestinal viruses, genetic susceptibilities, and lymphatic lesions associated with the development of human CD.

\section{Materials and Methods}

\section{Mice}

Female specific pathogen free $129 \mathrm{~S} 6 / \mathrm{SvEv}-$ Stat1tm1Rds $\left(\right.$ Stat $\left.^{-/-}\right)$mice, aged 4 to 6 weeks, were purchased from Taconic (Hudson, NY). Specific pathogen free interferon (Ifn) $\alpha \beta \gamma \mathrm{R}^{-1-}$ mice on a $129 / \mathrm{SvEv}$ background (AG129) ${ }^{30}$ were a kind gift from Dr. Michael Gale (University of Washington, Seattle, WA). Because sex-linked differences in disease kinetics are observed in some other IBD models, these studies were performed in female mice. Mice were group housed in autoclaved individually ventilated cages (Thoren, Hazleton, PA) with corncob bedding (The Andersons, Maumee, $\mathrm{OH}$ ), fed standard irradiated rodent chow (Purina Lab Diet 5053; Purina, Brentwood, MO), and provided with acidified, autoclaved, reverse osmosis-filtered water in bottles. Mice were maintained in a Helicobacter- and MNV-free colony and were screened for rodent pathogens by either monitoring of sentinel mice [Crl:CD1(ICR); Charles River, Wilmington, MA] or exhaust air duct PCR testing (mouse hepatitis virus, mouse parvovirus, epizootic diarrhea of infant mice virus, MNV, Helicobacter spp., minute virus of mice, pneumonia virus of mice, Reovirus type 3, Sendai virus, Theiler murine encephalomyelitis virus, lymphocytic choriomeningitis virus, Ectromelia virus, Mycoplasma pulmonis, pinworms, and fur mites). Mice were monitored and, at predetermined study end points, humanely euthanized by carbon dioxide gas exposure, followed by complete necropsy. Group sizes were determined on the basis of our initial pilot study, where $n=5$ per group yielded statistically significant differences in large-bowel inflammation. In studies in which infected mice were treated with different agents, group sizes were selected to detect approximately a $30 \%$ difference in means between the groups. All animal procedures were approved by the University of Washington's Institutional Animal Care and Use Committee.

\section{Viral and Bacterial Infections and Confirmation of Infection}

Mice were infected with one of two different isolates of MNV-4 (MNV-4 $4^{\mathrm{C}}$ and MNV-4 $\left.{ }^{\mathrm{H}}\right)^{31}$ or one untyped MNV $\left(\mathrm{MNV}^{\mathrm{UW}}\right)$. MNV-4 stock was obtained from the University of Missouri. ${ }^{21}$ MNV-4 ${ }^{\mathrm{C}}$ (https://www.ncbi.nlm.nih.gov/ nuccore; accession number MG298797.1) was used at a low viral passage (passage 7), whereas $\mathrm{MNV}-4^{\mathrm{H}}$ (https://www.ncbi.nlm.nih.gov/nuccore; accession number MG298798) was used at an unknown viral passage number. MNV-4 was propagated on RAW 264.7 cells, and viral stocks were quantified as previously described. ${ }^{23,32}$ Most of the studies were performed with $M N V-4^{\mathrm{C}}$ because no differences in disease were noted in mice infected with either isolate. Use of the MNV-4 ${ }^{\mathrm{H}}$ isolate is noted in relevant figure legends or tables. Mice were inoculated by oral gavage with clarified cell lysate of MNV-4-infected RAW 264.7 cells (approximately $1 \times 10^{6}$ plaque-forming units). Uninfected controls were gavaged with clarified RAW 264.7 cell lysate. MNV UW was isolated from aseptically collected mesenteric lymph nodes (MLNs) from a sentinel mouse housed in a different animal facility on campus that was positive for MNV via fecal RT-PCR. MLNs were homogenized using Lysing Matrix D Tubes (MP Biomedical, Solon, OH) in Dulbecco's modified Eagle's medium (DMEM) $+10 \%$ fetal bovine serum and 1\% penicillin/streptomycin (growth media), and clarified supernatant was used to infect RAW 264.7 cells. Although no cytopathic effect was noted after 6 days (in contrast to the behavior of MNV-4 isolates), cultures tested positive for MNV by RT-PCR. ${ }^{21}$ Virus was amplified by two additional blind passages in RAW 264.7 cells, and the virus concentration in the resulting lysate 
$\left(2.9 \times 10^{9}\right.$ viral genome copies/mL supernatant $)$ was quantified by quantitative real-time RT-PCR (RT-qPCR) using a DNA plasmid standard generated with previously published MNV-specific primers. ${ }^{21}$ To compare $\mathrm{MNV}^{\mathrm{UW}}$ with other available MNV sequences, a 5360 bp segment of the $\mathrm{MNV}^{\mathrm{UW}}$ coding sequence was amplified from cDNA synthesized with RNA isolated from infected RAW cells and subjected to shotgun sequencing (MRDNA, Shallowater, TX). Sequence similarity of the assembled contig compared with other MNVs was determined by using BLASTN searching the $\mathrm{nr}$ nucleotide database. MNV-4 (https://www.ncbi.nlm.nih.gov/nuccore, accession number DQ223043.1) had the highest sequence similarity to the $\mathrm{MNV}^{\mathrm{UW}}$ sequence (https://www.ncbi.nlm.nih.gov/ nuccore, accession number MG786810) at 94\%. Infection status for MNV was confirmed as positive or negative by fecal RT-PCR ${ }^{33}$ on pooled feces from individual cages collected at the start and end of each study. Rhesus rotavirus $[R R V(G)]$, originally obtained as a gift from Monica M. McNeal (Cincinnati Children's Hospital Medical Center, Cincinnati, OH) was thawed and diluted in DMEM to a final concentration of $1 \times 10^{7}$ plaqueforming units $/ \mathrm{mL}$. Mice were inoculated with $1 \times 10^{6}$ plaque-forming units RRV(G) in DMEM or DMEM alone (controls) via oral gavage.

\section{Tissue Collection and Histopathology}

At predetermined end points ranging from 3 days to 9 weeks postinfection (p.i.) with $\mathrm{MNV}$, blood was collected via cardiocentesis immediately after euthanasia and serum frozen in aliquots at $-80^{\circ} \mathrm{C}$. Sections of MLN, cecum, cecal contents, small intestine, liver, and spleen were collected in $250 \mu \mathrm{L}$ RNAlater stabilization solution (Qiagen, Hilden, Germany) or immediately frozen using dry ice or liquid nitrogen and stored at $-80^{\circ} \mathrm{C}$ until RNA, DNA, or protein extraction. Bone marrow was collected from hind limbs by flushing both the femur and tibia with phosphate-buffered saline solution containing $5 \%$ heat-inactivated fetal bovine serum (Atlanta Biologicals, Flowery Branch, GA).

Tissues including spleen, liver, cecum, MLN with mesentery, colon, and small intestine were immersion fixed in $10 \%$ neutral-buffered formalin, embedded in paraffin, sectioned, and stained with hematoxylin and eosin. Sections of cecum and Swiss-rolled proximal, mid, and distal colon were scored (range, 0 to 64 ) for typhlocolitis by a pathologist (P.M.T.) masked to experimental groups using a previously published scoring system. ${ }^{23}$ Briefly, each section of large bowel was scored for mucosal hyperplasia, inflammation, and extent of disease. The MLN and surrounding mesentery were assessed for lymphangitis, lymphangiectasia, hyperplasia, and inflammation with mesenteric lymphadenitis and surrounding regional lymphangitis; MLNs were scored by a previously reported method with modifications. ${ }^{22}$ Sections of liver and spleen were scored for pyogranulomatous to granulomatous hepatitis and splenitis; cholangiohepatitis was also scored. Inflammation scores in the spleen and liver reflected severity and extent of inflammation, with a range of 0 to 12 or 0 to 16 for the spleen and liver, respectively.

\section{Immunohistochemistry}

Immunohistochemistry was performed by the Pathology Research Services Laboratory (Department of Pathology, University of Washington). Formalin-fixed paraffin-embedded tissue sections were deparaffinized and rehydrated through graded ethanol series. Endogenous peroxidase was blocked by incubation in 3\% hydrogen peroxide, and the tissue sections were subjected to antigen retrieval in citrate buffer, $\mathrm{pH} 6$, using a Decloaking Chamber (Biocare Medical, Concord, CA), followed by blocking with Background Buster (Innovex Biosciences, Richmond, CA) for 1 hour at room temperature. Tissue sections were then incubated overnight at $4^{\circ} \mathrm{C}$ with the following primary antibodies diluted 1:100: anti-lymphatic vessel endothelial hyaluronan receptor $1^{33}$ (Abcam, Cambridge, MA), anti-CD3 (Dako, Carpinteria, CA), or anti-B220 (Becton Dickenson, Franklin Lakes, NJ). Bound antibody was detected with DAB Quanto Chromogen (Thermo Fisher Scientific, Waltham, MA) after incubation with species-matched ImmPress-HRP secondary polymer (Vector Laboratories, Burlingame, CA), as described by the manufacturer. Hematoxylin was used for counterstain.

\section{RNA Isolation, RT-qPCR Assays, and Expression Arrays}

Total RNA was extracted from MLN, cecum, spleen, and liver tissues using the RNeasy Mini RNA Isolation kit (Qiagen) with on-column DNase treatment, as per the manufacturer's instructions. One microgram of RNA was converted to cDNA with oligo-dT using the Invitrogen firststrand cDNA kit. Real-time PCR was performed to assess expression changes using gene-specific primers and Power SybrGreen (Applied Biosystems, Foster City, CA) on an MX3005P qPCR instrument [Stratagene (Agilent), Santa Clara, CA]. Quantitative PCR was used to determine MNV copy number present in the MLN, liver, and spleen of infected mice, as already described above. Previously published primer sequences were used for $I l 6,{ }^{23} \mathrm{Illb},{ }^{34} \mathrm{Hprt},{ }^{34}$ Illo, ${ }^{35} \mathrm{Tnfa}^{23}{ }^{23} \mathrm{Ifnb},{ }^{36} \mathrm{Vegfc},{ }^{37}$ and Vegfd. ${ }^{38} \mathrm{Il} 7$ primer sequences were from Primer Bank. Some sequences were designed in house: Ifng, 5'-GGATGCATTCATGAGTATTGC-3' (forward) and 5'-CCTTTTCCGCTTCCTGAGG$3^{\prime}$ (reverse); cMyc, 5'-CGATTCCACGGCCTTCTC-3' (forward) and $5^{\prime}$-TCTTCCTCATCTTCTTGCTCTTC- $3^{\prime}$ (reverse); inducible nitric oxide synthase (iNos), 5'GGAATCTTGGAGCGAGTTGT- $3^{\prime}$ (forward) and $5^{\prime}$ CCTCTTGTCTTTGACCCAGTAG-3' (reverse); and vascular endothelial growth factor receptor 3 (Vegfr 3 ), 5' GTGATCCAGGATGCCAATGT-3' (forward) and 5'GGTGGTCACATAGAAGTAGATGAG-3' (reverse). 
For expression arrays, total RNA was isolated from MLN, as above, and samples were pooled by mixing equal amounts of RNA from three to four mice from each treatment group (500 ng of total RNA). cDNA was synthesized from the pooled total RNA [RT2 first-strand cDNA kit (Qiagen)], which was then used to evaluate gene expression changes in the Janus kinase-STAT signaling pathway by real-time quantitative PCR Array plate (Qiagen/SABiosciences; PAMM-039). Fold change was determined using the $\Delta \Delta \mathrm{Ct}$ method. Data analysis was performed using the web-based RT2 Profiler PCR Array data analysis tool (http://saweb2.sabiosciences.com/pcr/arrayanalysis. php; SABiosciences, Frederick, MD, last accessed August 31, 2017), with housekeeping genes, Gusb3 and Gapdh, used as controls for normalization. Expression of select genes were then validated by RT-qPCR (as described in the first paragraph of this section) using individual samples and primer sets purchased to match those from the array.

\section{$\mathrm{TCID}_{50}$ Assay}

Flash-frozen tissues from MNV-4-infected mice were homogenized in $1 \mathrm{~mL}$ of growth medium using Lysing Matrix D tubes (MP Biomedical) for 60 seconds at $60 \mathrm{~Hz}$. Samples were then clarified by centrifugation. Supernatants were serially diluted, and 50\% tissue culture infective dose $\left(\mathrm{TCID}_{50}\right)$ assays were performed using RAW 264.7 cells, as described. $^{39,40}$

\section{Neutralizing Antibody Assay}

MA-104 cells (gift from Monica M. McNeal) were cultured in DMEM supplemented with $10 \%$ fetal bovine serum (Sigma-Aldrich, St. Louis, MO), $4 \mathrm{mmol} / \mathrm{L}$ L-glutamine, $100 \mathrm{U} / \mathrm{mL}$ penicillin, $100 \mu \mathrm{g} / \mathrm{mL}$ streptomycin, and 0.1 $\mathrm{mmol} / \mathrm{L}$ nonessential amino acids (complete DMEM). Trypsin-activated $\mathrm{RRV}(\mathrm{G})$ was propagated on MA-104 cells in serum-free DMEM. Serial dilutions of cleared lysate from cells infected with RRV were used to infect MA-104 cells in black wall, clear-bottom 96-well plates. Cells were fixed and stained with a rabbit anti-rotavirus antibody $^{41}$ (gift from Monica M. McNeal) and an Alexa Fluor 488-conjugated secondary antibody, and total well fluorescence was quantified with a Typhoon 9400 variable mode imager (GE Healthcare, Little Chalfont, UK) 24 hours after infection. Neutralizing antibody assays used a virus concentration producing $50 \%$ to $80 \%$ maximal signal. Twofold serial dilutions of heat-inactivated $\left(56^{\circ} \mathrm{C}\right.$ for 45 minutes) serum from mice were incubated with trypsinactivated $\operatorname{RRV}(\mathrm{G})$ for 45 minutes at room temperature and added to a confluent monolayer of MA-104 cells in 96-well plates. After 24 hours, cells were stained for rotavirus antigens and scanned, and background-subtracted fluorescence was quantified using ImageJ software version $1.48 \mathrm{k}(\mathrm{NIH}$, Bethesda, MD; http://imagej.nih.gov/ij). Fluorescence values were compared to control wells infected in the absence of serum. Neutralizing antibody titers are the reciprocal dilution of serum resulting in 50\% inhibition of infection and were determined by nonlinear regression using Prism software version 7.0a (GraphPad Software, La Jolla, CA). For serum samples that did not inhibit viral infection of MA-104 cells, the lowest dilution factor tested (8) was assigned. Neutralizing antibody titers were log transformed and compared by one-way analysis of variance with Bonferroni post-tests using Prism software.

\section{Microbiota Depletion by Antibiotics}

Mice were treated with broad-spectrum antibiotics to significantly deplete resident gut microbiota. Peanut butter-flavored antibiotic solution containing $100 \mathrm{mg} / \mathrm{mL}$ ampicillin, $100 \mathrm{mg} / \mathrm{mL}$ neomycin sulfate, $100 \mathrm{mg} / \mathrm{mL}$ metronidazole benzoate, and $50 \mathrm{mg} / \mathrm{mL}$ vancomycin hydrochloride was obtained from a compounding pharmacy (Ballard Plaza Pharmacy, Seattle WA). ${ }^{42}$ A peanut butter-flavored Ora-Sweet Syrup (Perrigo, Allegan, MI) vehicle control was obtained from the same pharmacy. Mice were gavaged with $100 \mu \mathrm{L}$ of antibiotic solution or vehicle control once daily for 5 days beginning 8 days before infection. On day 5, antibiotic solution [for a final concentration of ampicillin (1 g/L), neomycin sulfate (1 g/L), metronidazole benzoate $(1 \mathrm{~g} / \mathrm{L})$, and vancomycin hydrochloride $(500 \mathrm{mg} / \mathrm{L})]$ or vehicle control was added to the water. Animals were maintained on medicated and acidified water for the duration of the study. Fresh fecal pellets were collected after 5 days and cultured to verify depletion of the microbiota. Samples were plated on Trypticase Soy Agar plates containing 5\% sheep blood (VWR, Radnor, PA) for aerobic culture and Brucella agar plates containing 5\% sheep blood, hemin, and vitamin K (VWR) for anaerobic culture. Anaerobic culture plates were maintained in anaerobic chambers (Oxoid Ltd., Basingstoke, UK) filled with 90\% nitrogen, 5\% hydrogen, and 5\% carbon dioxide gas mixture (Praxair, Danbury, CT). All plates were cultured at $37^{\circ} \mathrm{C}$ for 72 hours before colony counting.

\section{Evaluation of Bacteria by Culture and 16S rRNA Sequencing}

Sections of liver and spleen were collected aseptically from lysate-treated or MNV-4 ${ }^{\mathrm{H}}$-infected mice and were evaluated with aerobic and anaerobic cultures (Phoenix Labs, Seattle, WA). In addition, splenic tissues were submitted to the University of Missouri Metagenomic Center (Columbia, MO) for extraction of bacterial genomic DNA and sequencing of the hypervariable V4 region of the prokaryotic 16S rRNA gene. Samples were sequenced using the Illumina MiSeq platform to a depth of 20,000 to 40,000 reads per sample. Sequence data were curated and processed by the University of Missouri Metagenomic Center facility using previously published methods. ${ }^{43,44}$ In addition, MLN samples from the anti-cytokine antibody treatment study 
$(n=5$ per group, lysate versus MNV-4-infected-IgG controls) were evaluated for the presence of bacteria by $16 \mathrm{~S}$ rRNA PCR. Samples were homogenized using MP Bio Fast Prep Tissue and Cell homogenizer and Matrix E lysis tubes (MP Biomedicals, Santa Ana, CA) and incubated at $95^{\circ} \mathrm{C}$ for 5 minutes. DNA was then isolated (Qiagen DNeasy Blood and Tissue Kit) per the manufacturer's instructions. Amplification of 16S rRNA was performed using universal primers, as previously described. ${ }^{45}$

\section{Flow Cytometry}

MLNs were subjected to mild collagenase digestion, singlecell suspensions were prepared, and, using a hemocytometer, live cells were counted (trypan blue exclusion). Cells were stained with combinations of fluorescently labeled antibodies specific for (mouse) T-cell antigen receptor $\beta, \mathrm{CD} 8, \mathrm{CD} 4$, CD44, CD49b, CD21, CD23, B220, CD19, IgM, IgD, CD11c, CD11b, and GR1 (BD Biosciences, San Jose, CA; eBioscience, San Diego, CA; or Biolegend, San Diego, CA). Samples were fixed in Phosflow Fix Buffer (BD Bioscience) and analyzed on an LSRII cytometer (BD Bioscience) at the University of Washington Immunology Flow Cytometry Core Facility. Post-collection analyses were performed using FlowJo Single Cell Analysis software version 10.7 (FlowJo LLC, Ashland OR). Cell numbers of subsets were calculated by multiplying the percentage of the subset determined by flow cytometric analysis gating by the live cell count determined for MLNs harvested from each animal. Percentages of T and B cells were determined from a lymphocyte-sized gate on the basis of forward scatter-A versus side scatter (SSC)-A and single cells determined by forward scatter-A versus forward scatter-W. For myeloid cells, a larger forward scatter-A versus SSC-A gate to include granular cells was used. T cells were characterized by staining with anti-T-cell antigen receptor $\beta$, CD8, CD4, and CD44 antibodies. CD19 ${ }^{+}$B220 ${ }^{+}$committed $\mathrm{B}$ cells were further separated into marginal zone $\left(\mathrm{CD} 21^{+} \mathrm{CD} 23^{+}\right)$versus follicular $\left(\mathrm{CD} 21^{+}, \mathrm{CD} 23^{-}\right) \mathrm{B}$ cells. Natural killer and natural killer $\mathrm{T}$ cells were determined on the basis of staining with anti-CD49b and T-cell antigen receptor $\beta$. Myeloid cells were gated as follows: neutrophils $\left(\mathrm{CD} 11 \mathrm{~b}^{+} \mathrm{Gr} 1^{+} \mathrm{CD} 11 \mathrm{c}^{-} \mathrm{SSC}^{\text {int }}\right), \mathrm{CD}_{11 b^{+}}$dendritic cell (DC; $\left.\mathrm{CD} 11 \mathrm{~b}^{+}, \mathrm{CD} 11 \mathrm{c}^{\mathrm{hi}}, \mathrm{Gr}^{-}\right), \mathrm{CD} 11 \mathrm{~b}^{-} \mathrm{DC}\left(\mathrm{CD} 11 \mathrm{~b}^{-}, \mathrm{CD} 11 \mathrm{c}^{\mathrm{hi}}\right.$, $\left.\mathrm{Gr}^{-}\right)$, plasmacytoid DC $\left(\mathrm{CD} 11 \mathrm{c}^{\mathrm{int}}, \mathrm{CD} 11 \mathrm{~b}^{-}, \mathrm{Gr}^{+}\right)$, granular subset $\left[\mathrm{SSC}^{\mathrm{hi}}, \mathrm{Gr}^{-}, \mathrm{CD} 11 \mathrm{~b}^{+}, \mathrm{CD} 11 \mathrm{c}^{+}\right.$(mostly $\left.\left.\mathrm{CD} 11 \mathrm{c}^{\mathrm{int}}\right)\right]$, monocytes, and macrophages $\left(\mathrm{CD}_{11} \mathrm{~b}^{+} \mathrm{CD} 11 \mathrm{c}^{-} \mathrm{Gr}^{-} \mathrm{SSC}^{\text {low }}->\mathrm{SSC}^{\mathrm{int}}\right)$.

\section{Anti-TNF- $\alpha$ and Anti-IFN- $\gamma$ Treatment of Mice}

InvivoPLUS anti-IFN- $\gamma$, anti-tumor necrosis factor (TNF)- $\alpha$, and rat IgG1 isotype control antibodies (Bio X Cell, West Lebanon, $\mathrm{NH}$ ) were diluted in sterile water and given to mice via i.p. injection twice weekly for 3 weeks. Doses were 200 (anti-IFN- $\gamma$ ) or 475 (anti-TNF- $\alpha$ or isotype) $\mu \mathrm{g} /$ mouse per injection, similar to previous studies, ${ }^{46,47}$ except for the last dose of anti-TNF- $\alpha$, which was given at $302 \mu \mathrm{g} /$ mouse. The first dose was given 1 day before infection of mice with MNV-4 (or lysate control).

\section{Serum Cytokine Determination and Analysis}

Frozen serum from MNV-4-infected or lysate control animals in studies performed at 3,7 , or 21 days p.i. were assayed (one assay per sample) with the 31-plex Mouse Cytokine Array/Chemokine Array (Eve Technologies Corp., Calgary, AB, Canada). Data values that returned below the limit of detection (out of range) were plotted as half the minimum value of the lowest value on the standard curve or the lowest extrapolated value for the assay (whichever value was lowest). The inverse was performed for data values above the highest standard curve value.

\section{Western Blot Analysis}

Single-cell suspensions were generated from MLN and bone marrow from wild-type $129 \mathrm{~S} 6 / \mathrm{SvEv}$ (WT) or $\mathrm{Statl}^{-1-}$ mice 7 days after infection with MNV-4. After washing with ice-cold phosphate-buffered saline, protein was extracted using M-PER containing Halt Protease and Phosphatase Inhibitors (Thermo Fisher Scientific, Waltham, MA). Total protein concentration was determined with the MicroBCA assay (Pierce/Thermo Fisher Scientific). Western blot analysis was performed, as previously described, ${ }^{48}$ with modifications. A total of 15 to 25 $\mu \mathrm{g}$ of protein was separated on a $10 \%$ MiniProtean precast gel (Bio-Rad, Hercules, CA). Signal was detected using SuperSignal Western Femto Chemilumiscent substrate (Thermo Fisher Scientific). Primary antibodies from Cell Signaling Technology (Danvers, MA) were P-STAT3 (clone 8H10D10), total STAT3 (clone 79D7), and P-STAT5 (clone C11C5). Primary antibodies from Thermo Fisher Scientific were P-STAT4 (polyclonal rabbit; catalog number 717900) and PSTAT6 (clone 46H1L12). Gels/bands were quantified using open-source ImageJ version 1.5. ${ }^{49}$

\section{Statistical Analysis}

Comparison of two groups was performed using two-tailed (unless otherwise specified) $t$-test or $U$-test for nonparametric comparisons. For inflammation scores determined by histologic analyses, multiple group comparisons were performed via nonparametric one-way analysis of variance (Kruskal-Wallis) followed by Dunn's post test for pairwise comparisons. In studies in which control (uninfected) groups were all zero values or close to zero, analysis of variance was performed only on infected treatment groups. $U$-test was used to compare pairwise to control groups. For flow cytometric analysis or MNV-4 genome copy assays, data with unequal variances (as determined via Bartlett's test) were square root, $\mathrm{Ln}$, or log transformed and parametric analysis of variance was performed with TukeyKramer post test. If transformation could not adjust 
variance differences, nonparametric analysis of variance (Kruskal-Wallis) was performed with Dunn's post test. Sample sizes were insufficient for normality tests. For serum cytokines, data values plotted, as described above, were subjected to parametric or nonparametric analysis of variance, as for flow cytometric analysis, except that Dunnett's or Dunn's post tests were used. Analyses were performed using Prism software version 5.04.

\section{Results}

MNV-4 Infection of Stat1 ${ }^{-/-}$Mice Results in Lesions in Liver, Spleen, MLN, Lymphatics, and Small and Large Bowel

To evaluate the in vivo behavior of MNV-4 isolates previously used in the laboratory, ${ }^{31} 105$-week-old female Stat $^{-1-}$ mice were infected with the two different MNV-4 isolates
(MNV-4 ${ }^{\mathrm{C}}$ and $\mathrm{MNV}-4^{\mathrm{H}}$ ), and body weight and clinical signs were monitored over 9 weeks p.i. Although body weight change (data not shown) was not affected and, generally, infected mice exhibited no clinical signs, MNV-4-infected Stat1 ${ }^{-1-}$ mice had lesions in liver, spleen, MLNs, and small and large intestine. There was pronounced hepatosplenomegaly characterized by multifocal pyogranulomatous to granulomatous hepatitis and splenitis (9 of 10 mice) (Figure 1, A, C, and D), marked lymphadenopathy of MLN with lymphangitis and lymphangiectasia (2 of 10 mice) (Figure 1, B and E), along with minimal to moderate segmental typhlocolitis (five of nine mice) (Figure 1E). No significant differences were noted between groups of mice infected with the two isolates and, therefore, most of the remaining histologic analyses of MNV-4-infected animals were performed using $\mathrm{MNV}-4^{\mathrm{C}}$.

To understand the progression of virus-induced lesions, histopathological changes in target organs were evaluated at
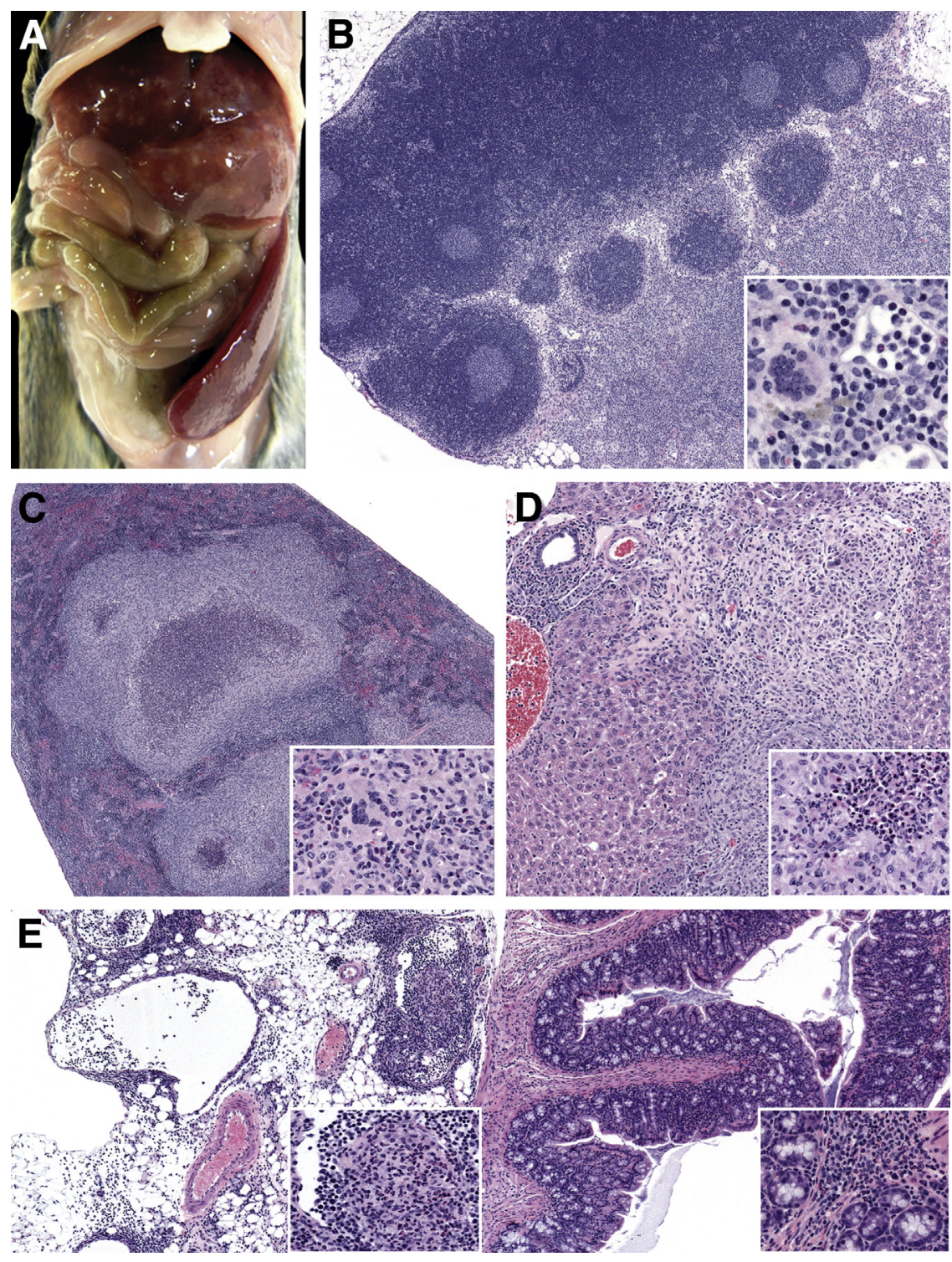

Figure 1 MNV-4-induced disease in Stat $1^{-/-}$ mice. Female Stat ${ }^{-1-}$ mice were infected with MNV-4 or gavaged with lysate control and necropsied 62 days p.i. A: Gross image of an MNV-4infected mouse with enlarged spleen and liver lesions. B: Enlarged mesenteric lymph nodes of the same mouse with higher magnification of attached mesentery shown in the inset. C: Spleen with inflammatory foci in another MNV-4-infected mouse. Inset: High magnification of pyogranulomatous foci. D: Liver with periportal inflammation and bridging pyogranuloma. Inset: Liver pyogranuloma. E: Colon and attached mesentery. Insets: Intralymphatic pyogranulomatous inflammation (left inset) and mild chronic-active mucosal inflammation (right inset). All histology panels are stained with hematoxylin and eosin. $n=10 \mathrm{MNV}-4$-infected $\left(5 \mathrm{MNV}-4^{\mathrm{H}}\right.$ and $\left.5 \mathrm{MNV}-4^{\mathrm{C}}\right)$; $n=3$ (lysate control). Original magnification: $\times 40$ (B, C, and E, main images); $\times 400$ (B, inset); $\times 100$ (D, main image, and $E$, inset) $\times 200$ ( $C$ and $D$, insets). 
earlier time points. A summary of the histologic lesions induced by MNV-4 infection over time is presented in Table 1. MNV-4 infection of Stat1 ${ }^{-/-}$mice initiated early transient lesions in the distal small intestine characterized on day 3 p.i. by mild neutrophilic, lymphocytic, and proliferative ileitis centered on hyperplastic gut-associated lymphoid tissue and some dilated lacteals (Figure 2). Lesions extended to the mesenteric lymphatic vessels and regional draining lymph nodes (MLNs) (Supplemental Figure S1), and although the MLN lesions persisted and worsened over time, the small intestine lesions resolved by day 7 (Table 1). By 3 weeks p.i., there was regional lymphangitis with dilated lymphatics variably obstructed by fibrinous to granulomatous thrombi. These lymphatics had mixed perilymphatic inflammation that extended into the regional mesentery (Figure 3). MLNs had moderate to severe granulomatous lymphadenitis with lymphangiectasia and efferent lymphangitis. Immunolabeling with anti-
LYVE-1, a marker of lymphatic endothelium, ${ }^{33}$ confirmed that inflamed and obstructed intestinal and MLN vessels were lymphatic (Figure 3). Segmental mucosal inflammation was noted at the ileocecocolic region and often associated with serosal and mesenteric lymphangitis with adhered mesentery (Table 1 and Figure 3). However, in some regions where there was severe mesenteric lymphangitis and serosal to tunica muscularis inflammation, the mucosa was spared. Hepatic and splenic inflammation was present by 7 days p.i. and persisted at later time points (Table 1). Minimal to moderate chronic-active large intestinal inflammation, characterized by lymphoplasmacytic infiltrates and multifocal regions of neutrophilic accumulation, was noted at later time points (19 days p.i.) in MNV-4-infected Stat1 ${ }^{-1-}$ mice (Supplemental Figure S2). One third (three of nine) of uninfected Stat $1^{-/-}$mice had mild lymphangitis or lymphadenitis by 3 weeks p.i., suggesting a tendency for Stat $^{-1-}$ mice to

Table 1 Time Course of Histologic Lesions in MNV-4-Infected Stat1 ${ }^{-/-}$Mice

\begin{tabular}{lll}
\hline Part of body & Day 3 after MNV-4 $(n=5)$ & Day 7 after MNV-4 $(n=6)$ \\
\hline Small intestine & Mild segmental neutrophilic, & Mostly normal, but 1 of 6 mice had \\
& lymphocytic, and proliferative & dilation in small intestine \\
& ileitis $(5 / 5)$ and dilated lacteals & mesentery with complete \\
& $(2 / 5)$ & obliteration of lymphatics
\end{tabular}

Large intestine

$\mathrm{MLN}^{\dagger}$

Ceca (in 3 of 5 mice) had minimal to mild lesions with focal lymphangiectasia of the lymphatics in the tunica muscularis, apoptosis of colonocytes, and minimal inflammation

(2/3, A subset of MLNs was examined) moderate to marked lymphoid hyperplasia

Liver None

Spleen

None
Normal (6/6), only occasional mild apoptosis of the dome epithelium of the GALT and minimal mucosal inflammation

$(3 / 3$, MLNs were evaluated in only 3 day 7 mice) progression of lymphoid hyperplasia and mild foci of neutrophilic, lesser histiocytic, lymphadenitis

(5/6 Mice) mild to moderate, primarily centrilobular, hepatitis, with some mice showing pyogranulomatous to granulomatous random hepatitis; one of these had severe chronic cholecystitis and cholangiohepatitis

(3/6 Mice) moderate multifocal histiocytic to pyogranulomatous splenitis and extramedullary hematopoiesis
3 Weeks after MNV-4 $(n=15)^{*}$

Mild rare segmental changes, villi with central accumulations of lymphocytes (13/15), and accumulations of apoptotic enterocytes within the lumen $(2 / 15)$

(14/15 Mice) mild segmental mucosal inflammation, often associated with serosal and mesenteric lymphangitis with adhered mesentery, dilated and inflamed variably obstructed lymphatics

(10/12 Mice) moderate to severe granulomatous lymphadenitis with lymphangiectasia and efferent lymphangitis

(15/15 Mice) chronic periportal proliferative cholangiohepatitis with epithelial hyalinization and eosinophilic crystals present within the bile duct lumens and random pyogranulomatous hepatitis

(9/15 Mice) moderate pyogranulomatous to granulomatous splenitis, lymphoid hyperplasia, and extramedullary hematopoiesis

${ }^{*}$ MNV-4-infected mice from two separate studies were compared; five animals were infected with MNV-4 ${ }^{\mathrm{H}}$, and 10 animals were infected with MNV-4 (controls from antibiotic study). No histologic abnormalities in these tissues were detected in wild-type mice infected with MNV-4 $(n=3,7$ days p.i.; $n=5$, 3 weeks p.i.).

${ }^{\dagger}$ In uninfected Stat $1^{-1-}$ mice, MLNs were mildly hyperplastic at day 7 p.i. At 3 weeks p.i., three of nine of uninfected Stat $1^{-/-}$mice had mild lymphangitis or lymphadenitis.

GALT, gut-associated lymphoid tissue; MLN, mesenteric lymph node. 

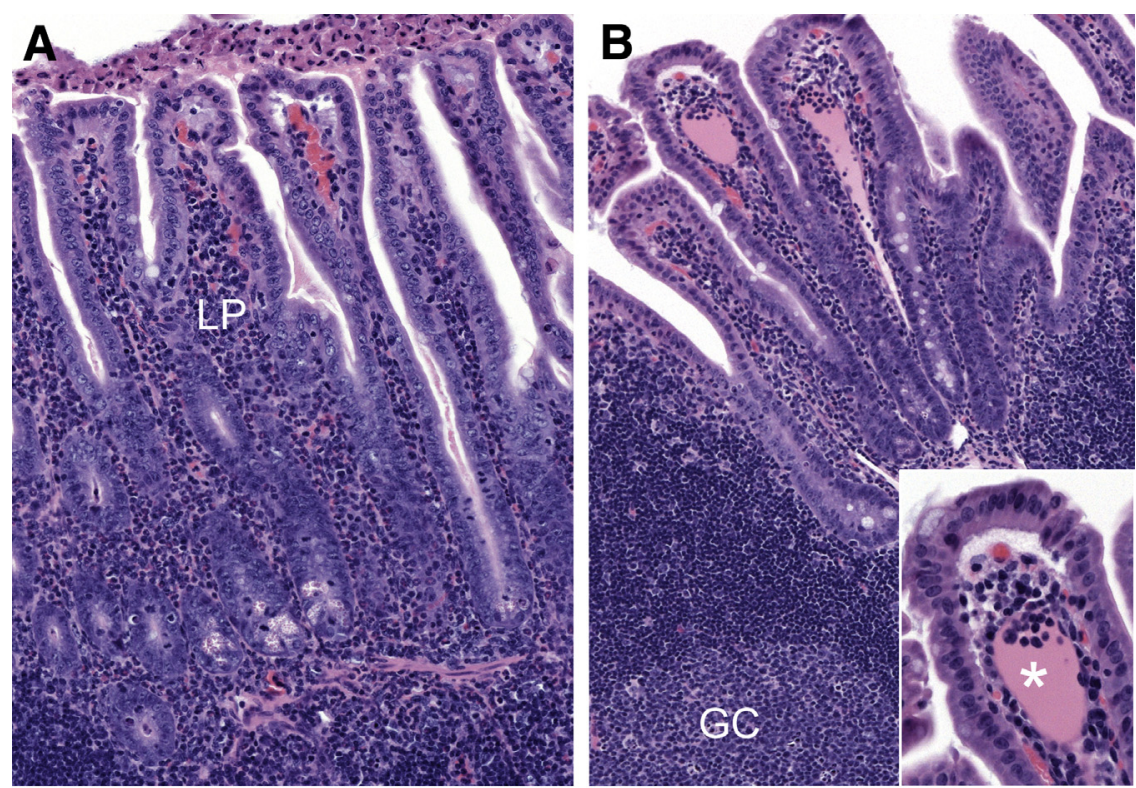

Figure 2 Small intestinal lesions in MNV-4infected Stat $1^{-1-}$ mice early after infection. A: At day 3 after MNV-4 infection, there is minimal to mild neutrophilic, lymphocytic, and proliferative ileitis centered on hypercellular gut-associated lymphoid tissue (GALT). B: Ectatic lacteals (asterisk) contain pink fluid and accumulations of mononuclear cells; GALT with germinal center (GC) is shown. Inset: High magnification of ectatic lacteal. C: Mixed neutrophilic and lymphocytic inflammation in the lamina propria (LP) with crypt
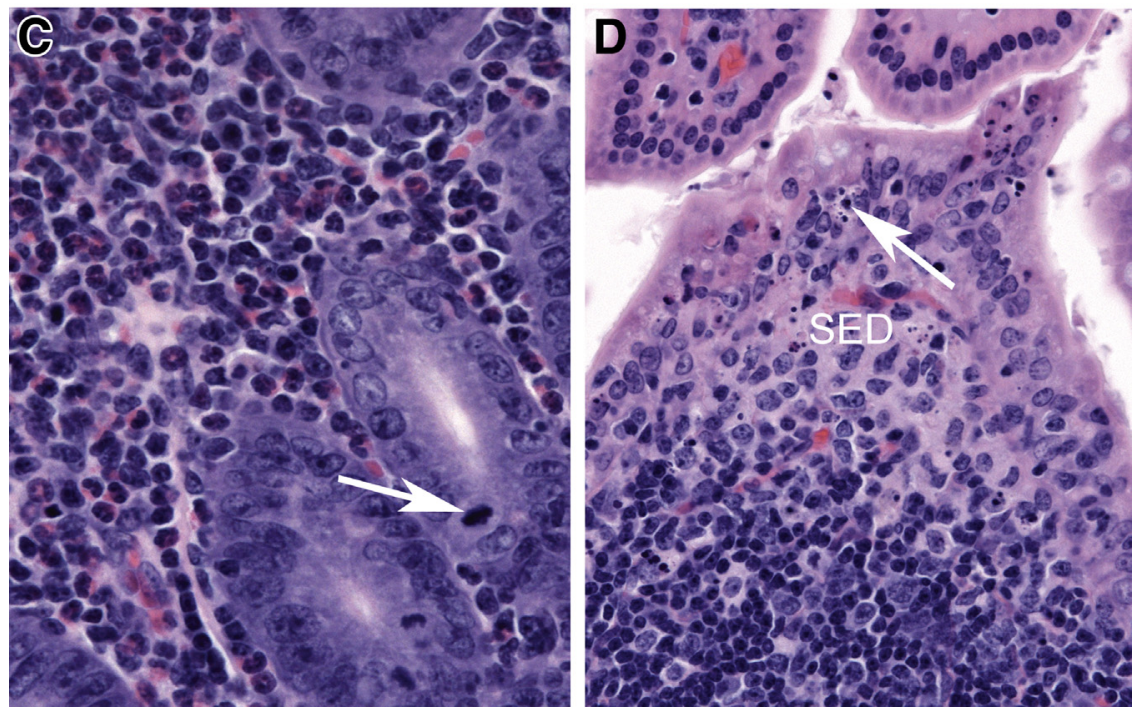
basophilia and prominent mitotic figures (arrow). D: Prominent apoptotic cellular debris in the follicle-associated epithelium (arrow) and the subepithelial dome region (SED) of Peyer's patch. Hematoxylin and eosin staining was used. A summary of these findings and animal numbers evaluated are presented in Table 1. Original magnification: $\times 100$ (A and $\mathbf{B}$, main image); $\times 200$ (B, inset); $\times 600$ (C); $\times 400$ (D).

develop spontaneous lymph node and lymphatic inflammation (data not shown). Histologic abnormalities seen in Stat $1^{-1-}$ mice were not detected in WT mice infected with MNV-4 (data not shown).

Together, these data suggest that early MNV-4-induced disease consists of initial changes in the small intestinal lymphatics and gut-associated lymphoid tissue, with extension to the mesenteric lymphatic vessels and regional draining lymph nodes (MLNs). This is followed by lesions in the liver and spleen, and finally establishment of chronic inflammation in the cecum and colon in MNV-infected Stat $1^{-/-}$mice at later time points.

\section{Stat $^{-/-}$Mice Infected with MNV-4 Are MNV-4 Positive in Multiple Organs and Have Higher Viral Loads than MNV-4-Infected WT Mice in Spleen and Liver}

To determine whether MNV-4 was present at sites where lesions occurred in Stat $^{-1-}$ mice, tissues were evaluated for the presence of MNV-4 by RT-PCR (using primers that detect multiple MNV strains). MNV-4 was detected at 20 days p.i. in all MLN, cecum, liver, and bone marrow samples tested from MNV-4-infected Stat ${ }^{-1-}$ mice $(n=10)$ and absent from uninfected mice $(n=5)$ (data not shown). RT-qPCR for MNV-4 at days 7 and 21 p.i. demonstrated that the abundance of MNV-4 genome copies in Stat $^{-1-}$ mice was similar in MLNs, but higher in liver and spleen compared with MNV-4-infected WT mice (Supplemental Figure S3), which showed no lesions with MNV-4 infection. To determine whether the MNV-4 genome copies detected by RT-qPCR correlated with infectious virus in Statl $^{-1-}$ mice, TCID $_{50}$ analysis was performed on the samples shown in Supplemental Figure S3. $\mathrm{TCID}_{50}$ assays of spleen and liver samples showed low (spleen) to no (liver) detectable infectious virus (data not shown). In MLNs, infectious virus was detected from three of three WT mice at day 7 p.i. (average, $5.13 \times 10^{5} \mathrm{TCID}_{50} / \mathrm{g}$ of tissue) compared with one of three Stat1 $^{-/-}$mice 

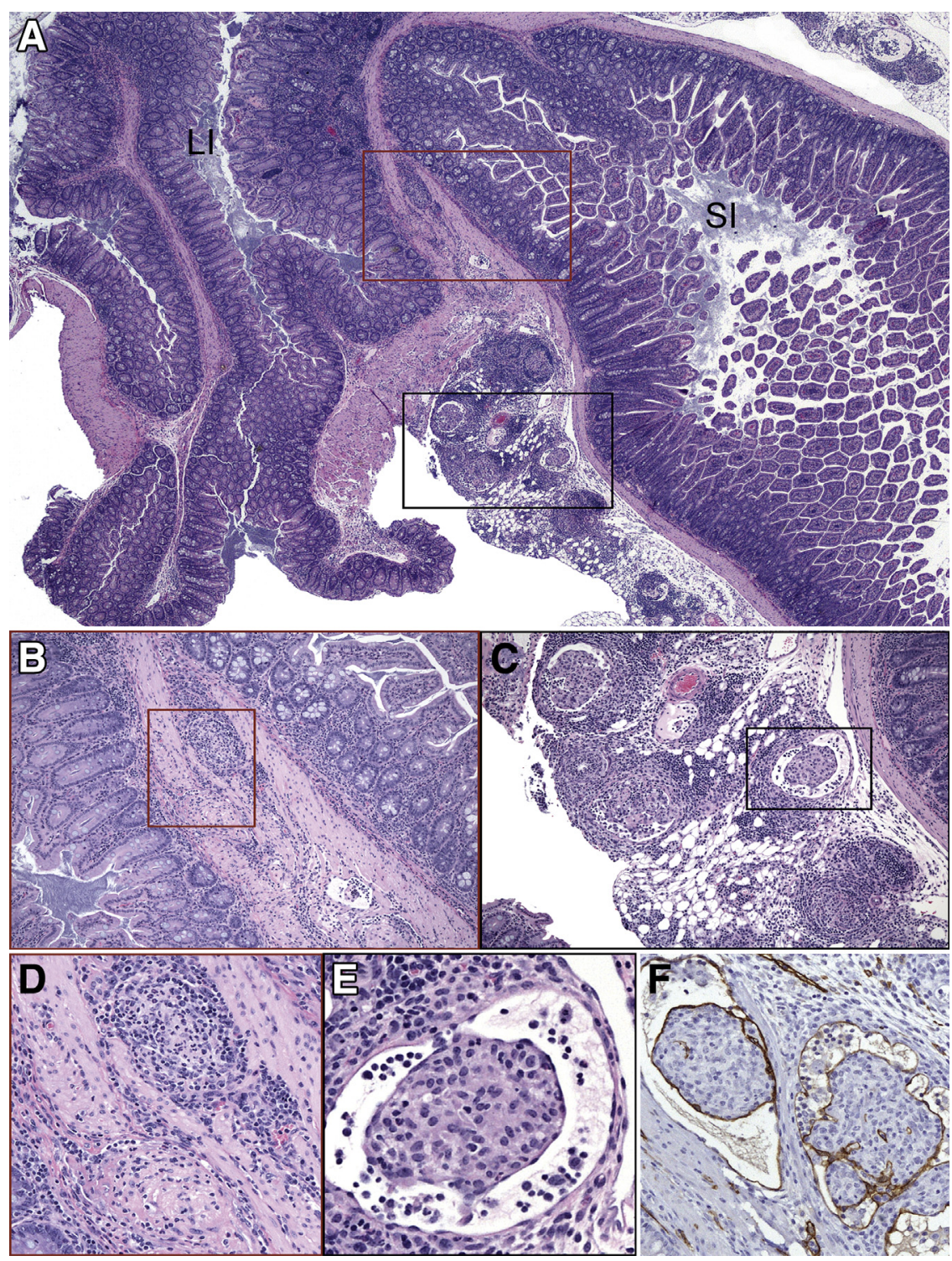

Figure 3 Regional lymphatic lesions in MNV-4infected Stat $1^{-/-}$mice at 21 days p.i. A: IIeocecocolic junction for orientation; large intestine (LI) and small intestine (SI) are indicated. There is severe inflammation of the regional lymphatics within the intestine and adherent mesentery. Boxed areas are shown at higher magnification in B and C. B-F: Lymphatics in the tunica muscularis and serosa are expanded and obliterated by dense accumulations of mononuclear cells within a fibrillary pink matrix admixed with low numbers of granulocytes. Mesenteric lymphatics are ectatic with intraluminal aggregates of mononuclear cells embedded in a pink fibrillary matrix surrounded by thin flat endothelium, which is LYVE-1 positive (brown staining). A summary of these findings and animal numbers evaluated are presented in Table 1. Boxed areas in $\mathbf{B}$ and $\mathbf{C}$ are shown at higher magnification in $\mathbf{D}$ and $\mathbf{E}$, respectively. Original magnification: $\times 40(\mathbf{A}) ; \times 100(B$ and $\mathbf{C})$; $\times 200$ (D and F); $\times 400$ (E). $\left(5.98 \times 10^{5} \mathrm{TCID}_{50} / \mathrm{g}\right.$ of tissue). At 21 days p.i., no cytopathic effect was detected in MLNs from either Stat ${ }^{-1-}$ or WT mice. In summary, MNV-4 viral load (genome copies) was higher in spleen and liver in Stat1 ${ }^{-1-}$ animals compared with WT, although infectious titer was not high enough to be determined by TCID $_{50}$ assay. Similar levels of virus (genome copies) were observed in MLNs at day 7, but infectious virus was more consistently detected in WT animals by $\mathrm{TCID}_{50}$ assay. These data suggest that presence of high levels of infectious viral particles is not required for development of histologic lesions in Stat $^{-/-}$mice.

\section{Another MNV Isolate Induces Similar Lesions in} Stat $^{-/-}$Mice, whereas Rotavirus Infection Does Not

Lesions were similar in StatI $^{-1-}$ mice infected with $\mathrm{MNV}^{\mathrm{UW}}$ (Supplemental Figure S4), an isolate from another mouse colony at the University of Washington that is behaviorally distinct because it produces no cytopathic effect in culture. Infection of Stat $^{-1-}$ mice with another enteric RNA virus (RRV) did not induce lesions when examined at 20 days p.i. Interestingly, although both the WT and Stat1 $^{-1-}$ mice seroconverted on RRV infection, neutralizing antibody titers were higher in Stat1 $^{-1-}$ mice compared with WT mice (data not shown). Therefore, two different MNV strains cause similar lesions in Stat1 $^{-1-}$ mice. A different type of RNA virus (rotavirus) did not cause these lesions in Stat $^{-/-}$mice, indicating that the response to $\mathrm{MNV}$ is unique and not simply an atypical immune response to any RNA virus.

\section{The Microbiome Does Not Affect MNV-4-Induced Lesions in Stat $1^{-/-}$Mice}

To test the role of the bacterial microbiome in the development of MNV-4-induced disease, antibiotic-treated MNV-4-infected Statl $^{-1-}$ mice were compared with 
MNV-4-infected mice not receiving antibiotics (Figure 4). Severity of the lesions was similar in both antibiotic-treated and untreated animals. Furthermore, lesion development did not appear to be directly caused by bacterial infection of extraintestinal organs. Aerobic and anaerobic cultures from spleen and liver from three $\mathrm{MNV}-4^{\mathrm{H}}$-infected mice failed to yield any bacterial organisms. 16S rRNA sequencing of MNV-4-infected splenic tissue $(n=5)$ resulted in only minimal amplification within samples (mean, 198 reads per sample), with $>93 \%$ of the reads failing to align with any known bacterial sequences. Of the operational taxonomic units that were detected from the splenic samples, all showed exceedingly low abundance (all $<8$ reads), and none of these operational taxonomic units were found to be present in all of the samples. In addition, there was no amplification of the $16 \mathrm{~S}$ rRNA gene by PCR from MLNs from MNV-4-infected mice (data not shown). These data suggest that the bacterial microbiome does not play a large role in MNV-4-induced lesion development in Stat $^{-1-}$ mice.

Innate and Adaptive Immune Cells Are Expanded in Draining Lymph Nodes from MNV-4-Infected Stat1 ${ }^{-/-}$ Mice

Because MLNs showed histologic changes after MNV-4 infection, MLN immune cell population changes were further defined by flow cytometric analysis. Consistent with the increased size of MLNs, the cell numbers of all myeloid and lymphoid lineage cell types increased with MNV-4 infection. However, the percentages of innate immune cells increased, whereas adaptive subsets remained similar or decreased (Figure 5). MNV-4 infection was associated with an increased ratio of $\mathrm{CD} 8^{+} / \mathrm{CD} 4^{+} \mathrm{T}$ cells at both time points, with increased expression of the activation/memory marker (CD44) in both subsets by 19 days p.i. (data not shown). For committed B cells, the ratio of follicular/marginal zone B cells decreased at day 5 p.i. but returned to control levels at day 19 p.i., consistent with a burst of marginal zone B-cell activity at day 5 compared with day 19. Natural killer cells increased significantly at day 5 p.i. and decreased by day 19 p.i. Natural killer $T$ cell numbers increased by day 5 p.i. and further increased by day 19 p.i.
(Figure 5). Among myeloid cell subsets, the highest fold increases were observed in both percentages and cell numbers of neutrophils, plasmacytoid DCs, and a granular $\mathrm{SSC}^{\mathrm{hi}}, \mathrm{Gr}^{-}$,

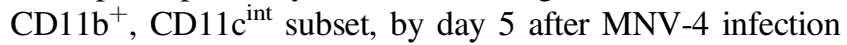
(Figure 5). These data indicate an expansion of immune cell subsets in MNV-4-infected Statl ${ }^{-1-}$ mice with a more marked increase in innate, particularly myeloid, cell subsets, compared with adaptive cell subsets.

\section{Genes and Proteins Associated with Inflammation and Lymphatic Function Are Altered in Serum, MLN, and Cecum after MNV-4 Infection}

To evaluate mechanisms by which MNV-4 induces disease, serum proteins associated with inflammation in uninfected controls and MNV-4-infected Stat ${ }^{-1-}$ mice were evaluated at three different time points. IFN- $\gamma$ and IFN- $\gamma$-induced protein 10 (CXCL-10), along with granulocyte colonystimulating factor (colony-stimulating factor-3), proteins were increased as early as day 3 p.i., whereas leukemia inhibitory factor, monokine induced by gamma interferon (CXCL-9), and IL-13 were elevated at later time points in MNV-4-infected animals (Table 2). No significant changes were noted in serum IL-6, IL-1 $\beta$, or IL-10, among others (data not shown). Interestingly, despite the increase observed in serum IFN- $\gamma$, no significant changes in IL-12p40/IL12p70 were observed (data not shown). Because intestinal inflammation was observed at day 21 p.i., cytokine gene expression was determined in MLNs and cecal tissue by RTqPCR. Average relative gene expression of Ifn $\gamma$ in MLNs increased 20-fold in MNV-4-infected animals compared with controls $(P=0.0078)$ (Table 3$)$. In cecal tissue, inflammatory mediators $I f n \gamma$, Tnf $\alpha$, and iNos were significantly increased in MNV-4-infected mice (59-, 16-, and 5.8-fold, respectively) (Table 3). Expression of genes involved in the function and remodeling of lymph vessels in IBD, ${ }^{51,52}$ Vegf-c, Vegf-d, and Vegfr3, were all moderately but significantly decreased (1.6 to 2.4-fold decreases) in cecal tissue from MNV-4-infected mice. In agreement with serum protein data, no significant differences were detected in $I l-6, I l-1 \beta$, or $I l-10$ expression.
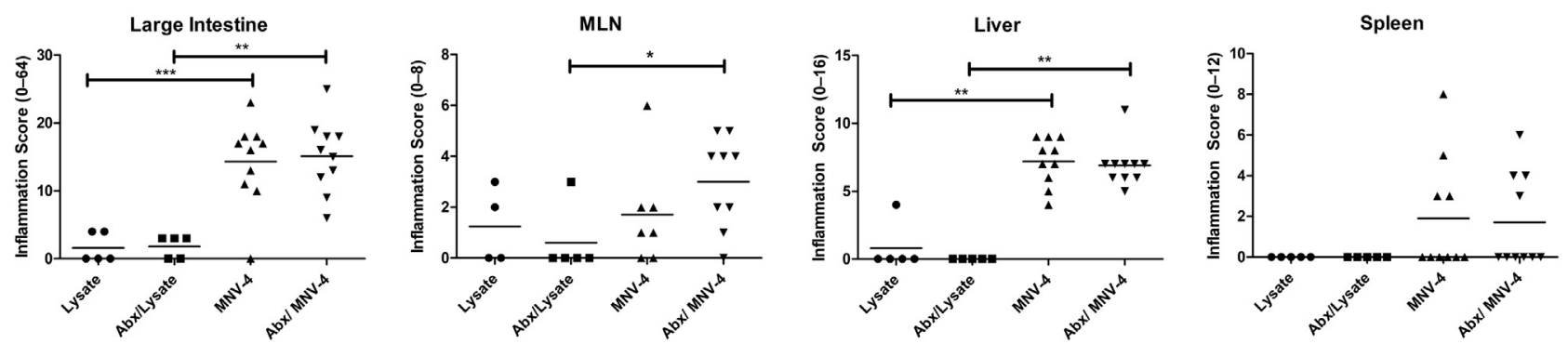

Figure 4 Evaluation of the role of gut bacteria in disease progression in MNV-4-infected Stat1 ${ }^{-/-}$mice. Stat1 ${ }^{-/-}$animals, aged 7 and 8 weeks, were gavaged with either control (flavored vehicle without antibiotics) or antibiotic solution for 5 days and then placed on antibiotic water for 3 more days before gavage with MNV-4 or lysate. Antibiotic water was continued for the duration of the experiment (20 days p.i.). Possible score range for each tissue is indicated on the $y$ axis (parentheses). Mesenteric lymph node (MLN) inflammation score is the summed adenitis and lymphangitis scores of MLN and any associated mesentery. Antibiotic treatment (Abx) does not produce significant differences in disease severity in MNV-4-infected mice. Significant pairwise comparisons are shown (U-test). ${ }^{*} P<0.05,{ }^{* *} P<0.01$, and ${ }^{* * *} P<0.001$. 
A

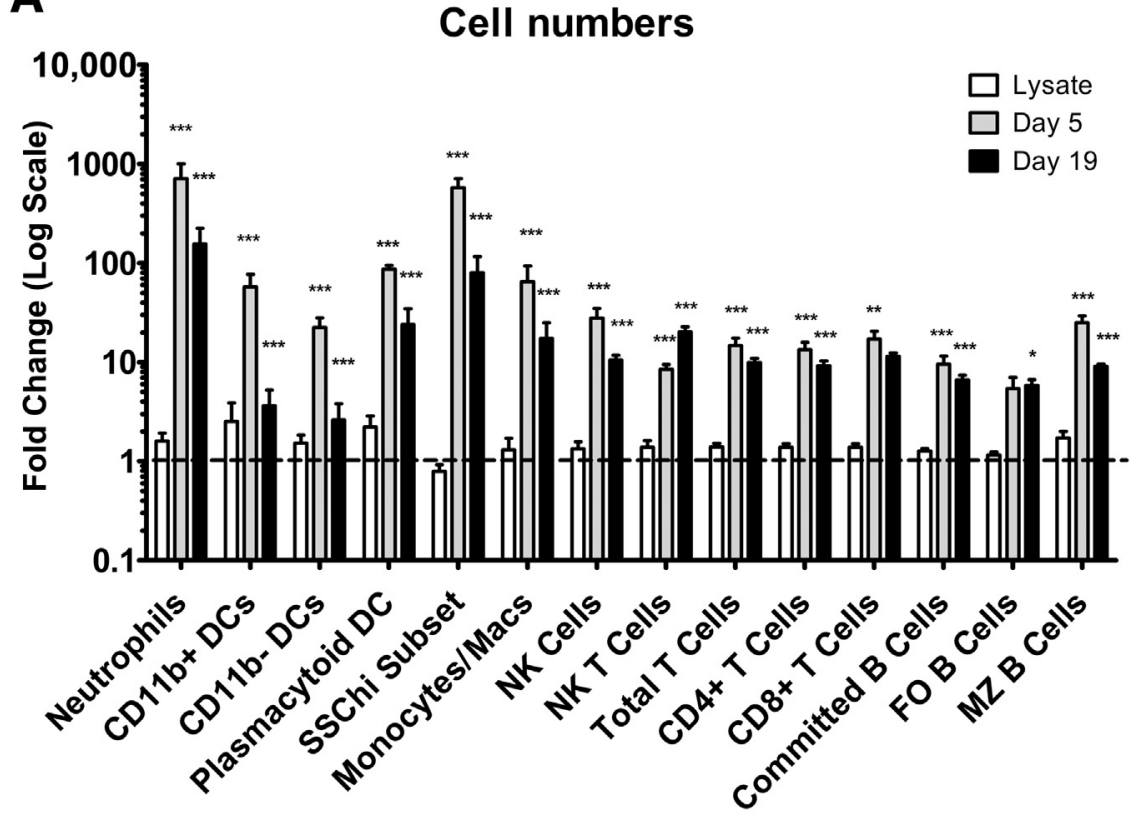

B

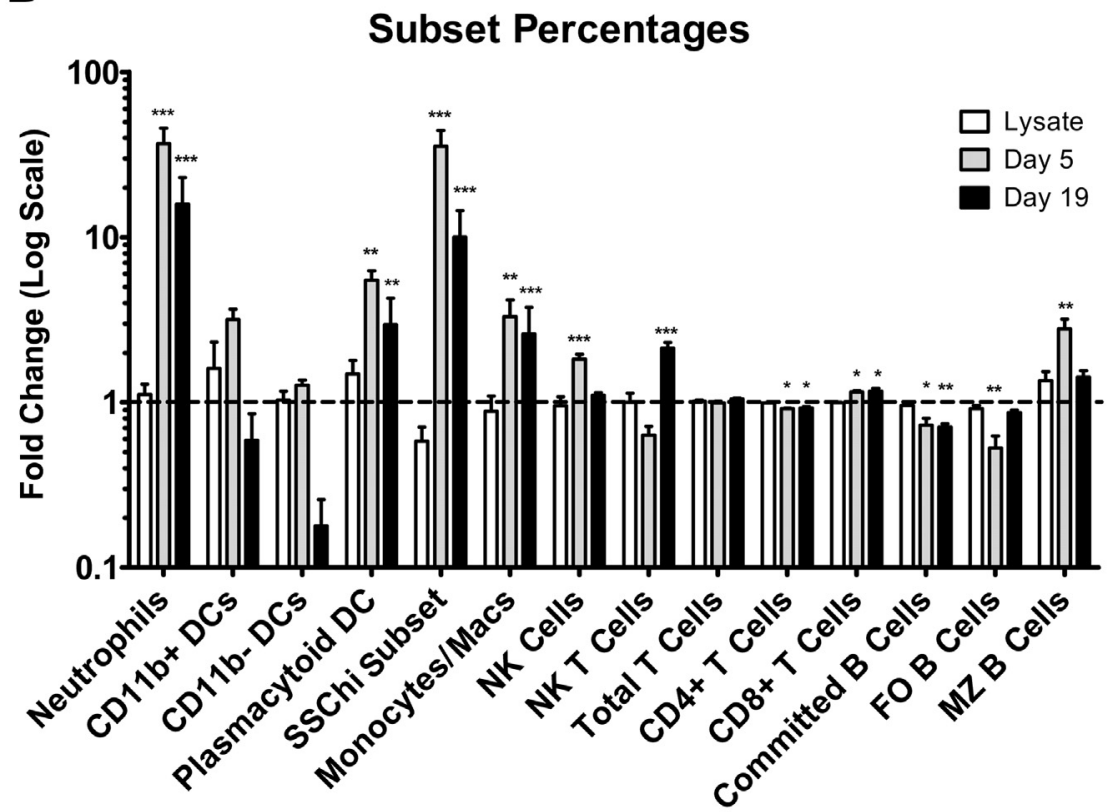

Figure 5 Changes in immune cells in MNV-4infected mesenteric lymph node (MLN). Absolute numbers (A) or percentage (B) of various MLN cell subsets was determined, and fold change compared with one arbitrary control sample was calculated for the three treatment groups. Data were compiled from two separate experiments (day 5 and day 19 p.i.), with lysate samples from both experiments combined into one group. The dashed line in each graph shows a fold change of one (no change from lysate). Significant differences compared with lysate control are indicated. $n=6$ (A and B, lysate, lymphoid cell subsets); $n=5$ ( $\mathbf{A}$ and $\mathbf{B}$, lysate, myeloid subsets, and days 5 and 19 after MNV-4 infection). ${ }^{*} P<0.05,{ }^{* *} P<0.01$, and $* * * P<0.001$. DC, dendritic cell; F0, follicular; MZ, marginal zone; NK, natural killer; SSC, side scatter.
Together, these data show elevated inflammatory mediators consistent with myeloid cell activation early after infection with MNV-4. Additional inflammatory genes are also expressed in the cecum at time points when intestinal lesions are present, whereas expression of genes involved in lymphatic function is decreased.

\section{Depletion of TNF- $\alpha$ and IFN- $\gamma$ Does Not Attenuate} Lesion Development in MNV-4-Infected Stat1 ${ }^{-/-}$Mice

Because elevated TNF- $\alpha$ and IFN- $\gamma$ are reported in human IBD patients and animal models of IBD $^{53}$ and levels of both cytokines were significantly increased in MLN and cecal tissues from MNV-4-infected Stat ${ }^{-1-}$ mice, it was determined if the multiorgan lesions could be suppressed by cytokine neutralizing antibodies. Stat $1^{-1-}$ mice were treated with anti-IFN- $\gamma$, anti-TNF- $\alpha$, or an isotype control antibody starting at 1 day before infection with MNV-4 and continuing twice weekly throughout the study period. Dosing regimens were followed for antiIFN- $\gamma$ and anti-TNF- $\alpha$ that showed decreased disease in a colitis-associated tumor development $\operatorname{model}^{46}$ and a mouse model of $\mathrm{IBD}^{47}$ respectively. Anti-cytokine treatments had only minimal effects on lesion severity 
Table 2 Fold Change of Serum Analytes in MNV-4-Infected Stat1 ${ }^{-/}$Animals at Different Time Points p.i. Compared with Uninfected Controls

\begin{tabular}{|c|c|c|c|c|c|}
\hline Analyte name & Other name & $\begin{array}{l}\text { Day } 3 \text { after } \\
\text { MNV-4 }(n=5)\end{array}$ & $\begin{array}{l}\text { Day } 7 \text { after } \\
\text { MNV-4 }(n=8)\end{array}$ & $\begin{array}{l}\text { Day } 21 \text { after } \\
\text { MNV-4 }(n=5)\end{array}$ & $\begin{array}{l}\text { Analysis of } \\
\text { variance } P \text { value }\end{array}$ \\
\hline G-CSF & CSF-3 & $3.74^{*}$ & 5.70 & 3.87 & 0.0113 \\
\hline IFN- $\gamma$ & & 3.28 & 13.9 & 2.83 & $0.006^{*}$ \\
\hline LIF & & -1.97 & 7.47 & 2.26 & 0.0261 \\
\hline MIG & CXCL9 & -1.10 & 2.70 & 3.39 & 0.0293 \\
\hline
\end{tabular}

Fold change was calculated by dividing the average value at the specified day by the average value for uninfected control mice. Where this change was a fraction, values were converted to show negative fold change ( $-1 /$ fractional value). Significance was determined by Dunnett's post-analysis of variance test in the case of parametric analysis of variance or Dunn's multiple comparison post-nonparametric Kruskal-Wallis test. Data are compiled from six individual studies. Significant differences when compared with uninfected controls are shown in bold. Only analytes with significant differences at one or more time points are shown. MIP-1 $\beta$, eotaxin, IL-15, granulocyte-macrophage colony-stimulating factor, IL-1 $\alpha$, IL-1 $\beta$, IL-2, IL-3, IL-4, IL-5, IL-6, IL-7, IL-9, IL-10, IL12p40, IL-12p70, IL-17, keratinocyte chemoattractant, MCP-1, macrophage colony-stimulating factor, MIP-1 $\alpha$, MIP-2, regulated on activation normal T cell expressed and secreted (RANTES), tumor necrosis factor- $\alpha$, and vascular endothelial growth factor-A were evaluated but were not significantly different with MNV-4 infection.

*Data could not be normalized via transformation; therefore, nonparametric analysis of variance was used (Kruskal-Wallis).

CSF, colony-stimulating factor; G-CSF, granulocyte CSF; IFN- $\gamma$, interferon- $\gamma$; IP, interferon gamma-induced protein; LIF, leukemia inhibitory factor; MIG, monokine induced by gamma interferon (CXCL-9); MIP, macrophage inflammatory protein.

assessed at 19 days p.i. (Figure 6), with similar degrees of colitis and hepatitis seen among the MNV-4-infected treatment groups. Inflammation in MLN and spleen was significantly increased in anti-IFN- $\gamma$-treated mice compared with isotype-treated control mice. These data support the notion that the elevated IFN- $\gamma$ and TNF- $\alpha$ are not contributing to increased disease severity in Statl $^{-/-}$ mice with MNV-4 infection and that IFN- $\gamma$ may be partially protective.

Table 3 Average Fold Change in Expression of Various Genes in MNV-4-Infected Stat1 ${ }^{-/-}$Mice Versus Uninfected Controls at Day 20 after MNV-4 Infection

\begin{tabular}{llc}
\hline & \multicolumn{2}{l}{ Fold change, $P$ value } \\
\cline { 2 - 3 } Gene & Cecum & MLN \\
\hline Cytokines & & \\
Ifn $\gamma$ & $58.93^{* *}$ & $12.61^{* *}$ \\
Tnfo & $15.93^{* * *}$ & 1.43 \\
iNos & $5.83^{* *}$ & 1.96 \\
Il1b & 1.28 & 2.48 \\
Il6 & 1.25 & 1.96 \\
Il10 & -1.47 & -1.45 \\
Ifn $\beta$ & -1.33 & ND \\
Il7 & $1.52^{*}$ & $-2.42^{* *}$ \\
Other genes & & \\
C-myc & -1.16 & -1.42 \\
Vegfr3 & $-2.41^{* *}$ & -1.53 \\
Vegfc & $-1.6^{*}$ & 1.37 \\
Vegfd & $-1.85^{* *}$ & -1.2 \\
\hline
\end{tabular}

Mice were control mice in antibiotic study treated with vehicle. Cecum: $n=10$ MNV-4 infected and $n=5$ uninfected. MLN: $n=6$ MNV- 4 infected and $n=4$ uninfected.

${ }^{*} P<0.05,{ }^{*} P<0.01$, and ${ }^{*} * P<0.001$.

${ }^{\dagger}$ Compared by two-tailed $t$-test (unadjusted for multiple comparisons). MLN, mesenteric lymph node; ND, not done.

\section{MNV-4 Does Not Induce Lesions in Mice Lacking IFN Receptors}

STAT1 is a downstream mediator of both type I and type II IFNs. To determine whether MNV-4-induced disease in Stat $^{-1-}$ mice was a result of inhibited IFN signaling in general, Ifn $\alpha \beta \gamma r^{-l-}$ mice were infected with MNV-4 and followed up for 19 days p.i. No clinical signs or weight loss was detected in either infected or uninfected mice (data not shown). In addition, MNV-4 infection in Ifn $\alpha \beta \gamma r^{-1-}$ mice did not result in any gross lesions in the small intestine, liver, spleen, cecum, or colon. Histologically, all tissues examined were normal in 11 of 12 mice; 1 of the $12 \mathrm{MNV}$ 4-infected mice had primarily necrotizing to pyogranulomatous and sclerosing lymphadenitis, hepatitis, and splenitis, which differed from the predominant pyogranulomatous lesions noted in MNV-4-infected Stat1 ${ }^{-/-}$mice (data not shown). Hence, Ifn $\alpha \beta \gamma r^{-1-}$ mice did not develop lesions similar to the Statl $^{-1-}$ mice when infected with MNV-4 (and no lesions were noted in uninfected controls), suggesting that the phenotype in MNV-4-infected Stat1 ${ }^{-1-}$ mice is not because of the failure of canonical signaling of interferons via their receptors.

\section{MNV-4 Infection Increases Expression Levels of Target Genes of STAT3, STAT4, and STAT5 Signaling and Decreases Those Targeted by STAT6}

In the absence of STAT1, virus-induced immune responses may be redirected through alternate Janus kinase/STAT signaling pathways. ${ }^{53}$ To determine how those pathways are altered in response to MNV-4 infection, the expression of Janus kinase/STAT pathway genes was evaluated in MLNs harvested at day 7 p.i. from infected and uninfected Statl $^{-1-}$ 

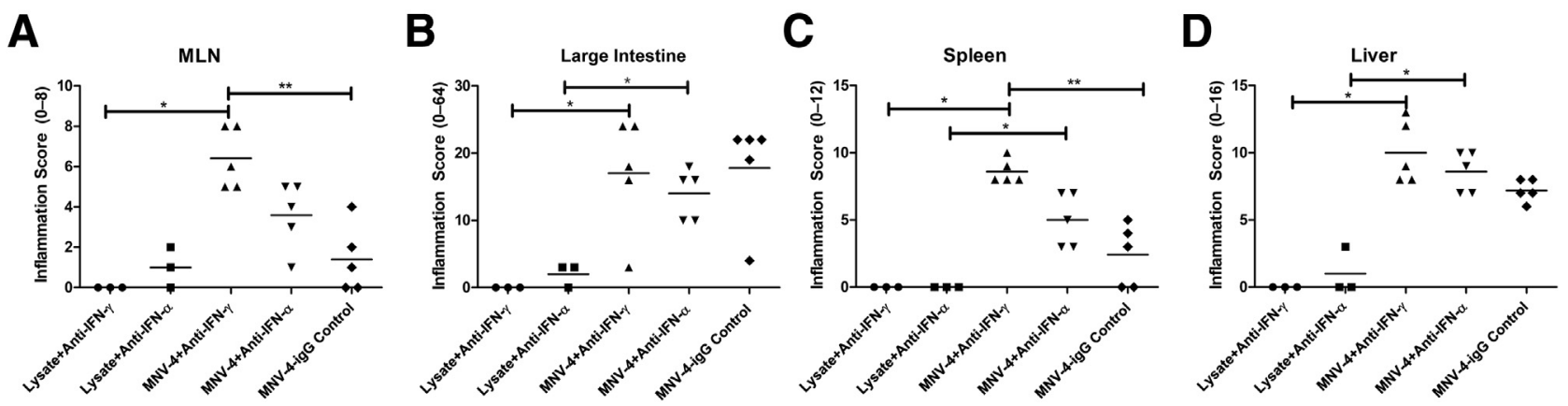

Figure 6 Anti-cytokine treatment of MNV-4-infected Stat $1^{-/-}$mice. Stat ${ }^{-/-}$.mice were treated with anti-interferon (IFN)- $\gamma$ or anti-tumor necrosis factor (TNF)- $\alpha$ antibodies 1 day before MNV infection, 2 days p.i., and then twice weekly for the duration of the study (20 days p.i.). Inflammation scores of mesenteric lymph node (MLN; A), colon (B), spleen (C) and liver (D) determined by histologic analysis are shown. Statistical comparison between MNV-infected groups was by nonparametric analysis of variance with Dunn's post test. MNV-4-infected mice were compared with lysate controls with the $U$-test. ${ }^{*} P<0.05,{ }^{*} * P<0.01$.

and WT mice. MLNs were used because lymphatic lesions were noted in this tissue at day 7. Pooled samples from two separate studies were evaluated, and a summary of the relative gene expression of MNV-4-infected mice compared with uninfected controls is shown in Supplemental Table S1. Cluster analysis of all STATactivated genes from one study shows that, of the genes induced by STAT3 (and not by other STATs), six of nine were expressed at much higher levels in infected Stat $1^{-1-}$ mice compared with any other treatment group (Figure 7). Genes induced by STAT6 were down-regulated compared with uninfected Stat1 ${ }^{-1-}$ mice. Expression levels of immune response genes induced by STAT3, $\operatorname{Lrgl}$, associated with neutrophil function, ${ }^{54}$ and $C e b p d$, a transcription factor associated with suppressor of cytokine signaling 3 signaling in macrophages, ${ }^{55}$ were increased in infected Stat $^{-1-}$ mice but were not changed or not detected in infected WT mice. In addition, the IBD biomarker $F \operatorname{cgrl},{ }^{56}$ the high-affinity receptor for the Fc portion of Ig $\gamma$ receptor (alias $C d 64$ ), which is linked to both STAT4 and STAT3 signaling, ${ }^{57}$ was up-regulated in infected Statl $^{-1-}$ mice.

\section{MNV-4 Induces Increased STAT3 Phosphorylation in Stat1 ${ }^{-/-}$Mice}

Because downstream genes of multiple STAT signaling pathways were significantly altered in $\mathrm{Statl}^{-/-}$mice on MNV-4 infection, it was evaluated whether the various STAT proteins were activated differently in response to MNV-4 infection by examining the phosphorylation status of STAT3, STAT4, STAT5, and STAT6 in MLNs to correlate results with gene expression changes. In addition, bone marrow cells isolated from MNV-4-infected and uninfected Stat $^{-1-}$ or WT animals 7 days p.i. were examined for STAT signaling changes because it was noted that cell subsets in this tissue were also altered with MNV-4 infection. ${ }^{58}$ Increased STAT3 phosphorylation was observed in MLNs (one of three experiments) (Figure 8A) and bone marrow cells (two of three experiments) (Figure 8B) from MNV-4 ${ }^{\mathrm{C}}$-infected $\mathrm{Stat1}^{-1-}$ mice. STAT4 or STAT5 phosphorylation was not detected in either bone marrow or MLNs (data not shown). Although STAT6 phosphorylation was detected in MLN samples, no significant changes were detected in response to MNV-4 infection (data not shown). These data, combined with the gene expression data, indicate that MNV-4 infection skews signaling toward STAT3 responses in the absence of STAT1.

\section{Discussion}

Murine Norovirus Infection of Stat $1^{-/-}$Mice Induces Lymphatic Changes Preceding Large Intestinal Inflammation Independent of Bacteria

In this report, it has been shown that Stat $^{-/-}$mice infected with MNV-4 develop disease characterized by initial transient changes in the small intestinal mucosa, lymphatics, and gut-associated lymphoid tissue, with extension to the mesenteric lymphatic vessels and regional draining lymph nodes (MLNs). This is followed by development of inflammatory lesions in the liver and spleen and, finally, establishment of mild to moderate chronic inflammation in the cecum and colon at later time points. No bacteria were detected in the lymph nodes, spleen, or liver of MNV4-infected mice, and MNV-4-induced lesions were not reduced when the gut microbiome was depleted by broadspectrum antibiotics. Another enteric virus, rotavirus, failed to recapitulate the lymphangitis and other inflammatory lesions in the liver, spleen, and large bowel, whereas two isolates of MNV (MNV-4 and $\mathrm{MNV}^{\mathrm{UW}}$ ) induced similar lesions. Lesions comparable to those we observed in liver and spleen have been observed in Statl $^{-1-}$ mice infected with another persistent MNV (MNV-07). ${ }^{59}$ MLNs were occasionally observed to be grossly enlarged with MNV-07 infection; however, lymphatic lesions and typhlocolitis were not noted in these studies. ${ }^{59}$

\section{The Role of Lymphatics in Colitis}

Abnormalities such as lymphangitis and lymphatic obstruction were observed in some of the early descriptions 


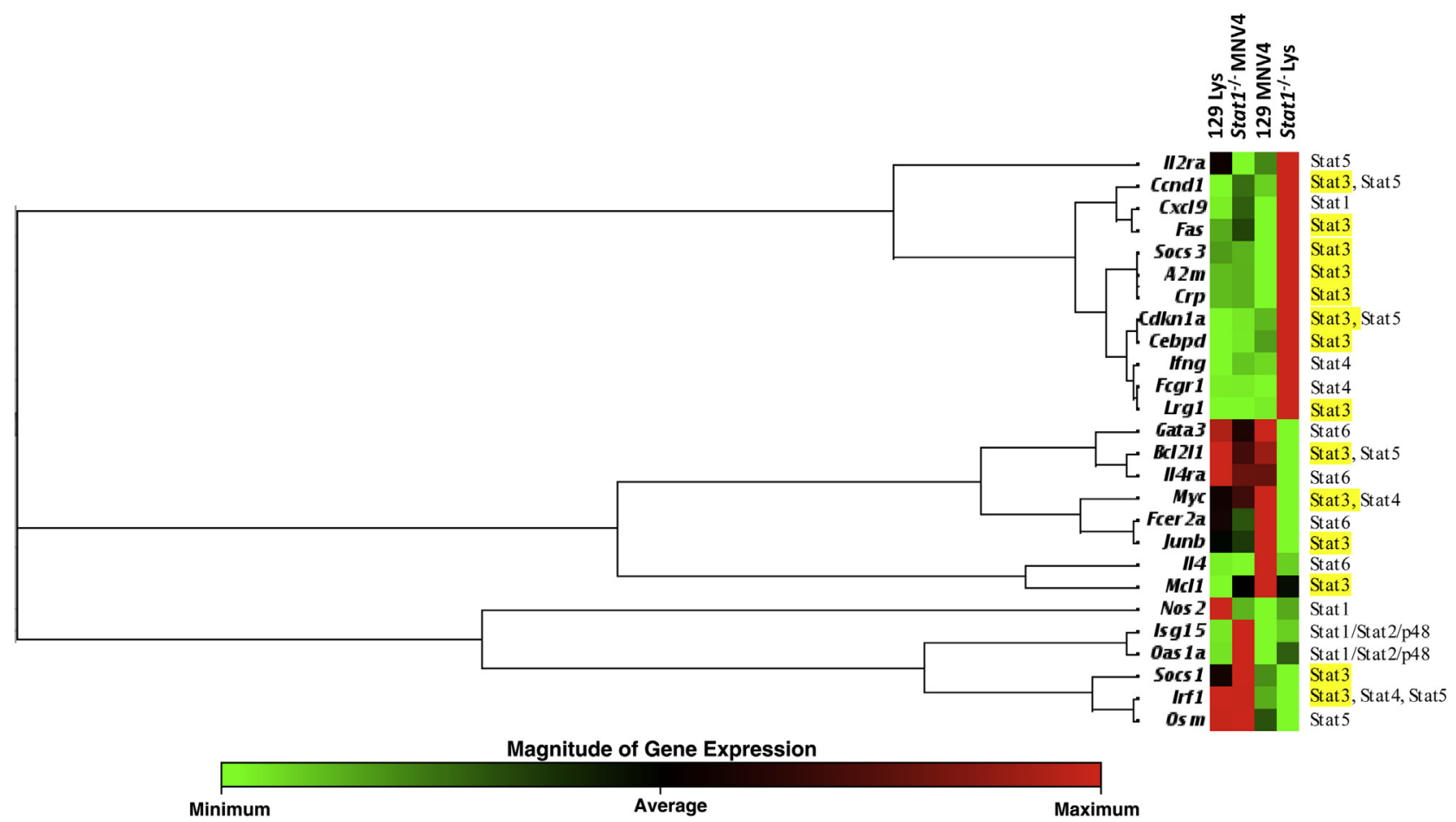

Figure 7 Mesenteric lymph node (MLN) Janus kinase/STAT array results in uninfected or MNV-4-infected (day 7 p.i.) wild-type and Stat1 ${ }^{-/-}$mice. A clustergram of STAT-induced genes generated by unsupervised clustering of fold change data normalized to the mean expression of all genes is shown. Dendrogram clusters represent coregulated genes. Shown at the right are the STATs associated with induction of each gene (as defined by Qiagen in the array), with STAT3-pathway associations highlighted in yellow.

of $\mathrm{CD}^{6}$ and have been observed in IBD patients who also show dilated lacteals and lymphatics. ${ }^{7,60}$ Increased lymphangiogenesis and vessel density have been observed in both diseased and normal tissues in human IBD patients, ${ }^{61}$ and changes in lymphatic vessel density may be predictive for CD recurrence. ${ }^{62}$ Lymphangitis is also closely linked with the pathogenesis of $\mathrm{CD} .{ }^{8,26}$ Recently, altered transport from lymphatic collecting vessels was shown in $\mathrm{CD}^{63}$ Although these observations, along with animal models of obstructed lymphatics, ${ }^{7}$ suggest lymphatic involvement in gut inflammation, the extent to which human IBD is caused by defective lymphatic function is still unclear. Addressing this issue in humans is difficult because we are unable to observe human disease development from its preclinical stages onward and, until relatively recently, few tools existed with which to study the role of lymphatic involvement in IBD pathogenesis.

In recent animal studies, Cromer et $\mathrm{al}^{9}$ reported that changes in lymphatic function preceded gut inflammation and that recovery of lymphatic function was associated with resolution of inflammation. In MNV-4-infected Stat1 ${ }^{-1-}$ mice, dilation of intestinal lymphatics was observed at early stages of infection. Lymphatic abnormalities persisted throughout the disease progression and were more pronounced by 3 weeks p.i. when inflammation in the cecum and colon was detected; these changes were associated with significant decreases in expression of Vegf-c, Vegf-d, and the lymphangiogenic receptor, Vegfr3. Similarly, in $\mathrm{C} 3 \mathrm{H} /$
HeJBir $I l-10^{-1-}$ mice ${ }^{64}$ blockade of VEGFR3 exacerbated colitis and was associated with increased lymphangiectasia. ${ }^{65}$ D'Alessio et $\mathrm{al}^{50}$ also showed that increased VEGF-C expression was beneficial in dextran sodium sulfate-induced and $\mathrm{Il}-10^{-/-}$colitis, whereas blockade of VEGFR3 exacerbated colitis. In contrast, Wang et $\mathrm{al}^{66}$ showed that overexpression of VEGF-C in dextran sodium sulfate-treated mice exacerbates colitis at an acute time point. These authors suggest that the discrepancy between the two studies could be because of proangiogenic effects of VEGF-C during the acute time point that could overpower the ability of the lymphatic system to aid in abetting inflammation. The data from our studies and these other animal models indicate decreased lymphatic function associated with increased disease severity and occurrence. Although studies performed in IBD patients show increased vessel density ${ }^{50,60,61,67}$ and increased expression of lymphangiogenic factors (including increased VEGF-D and VEGF-C protein), ${ }^{50,68}$ increased lymphangiogenesis is likely adaptive during inflammation and several modifiers may be needed to generate fully functional lymphatic channels. This is illustrated in animal studies by Becker et $\mathrm{al}^{4}{ }^{4}$ where a genetic abnormality associated with reduced lymphatic drainage increased dextran sodium sulfate-induced disease severity despite intact lymphangiogenesis in response to inflammation. Many human IBD studies do not address functionality of the vessels, as has been done by Tonelli et al, ${ }^{69}$ making it difficult to 
A
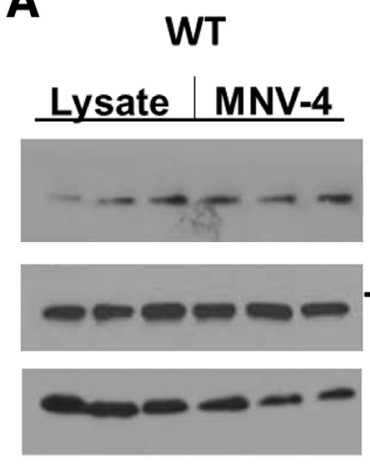

B

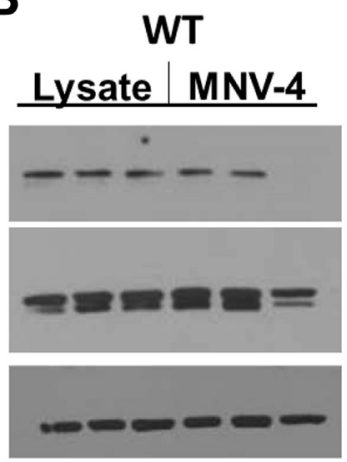

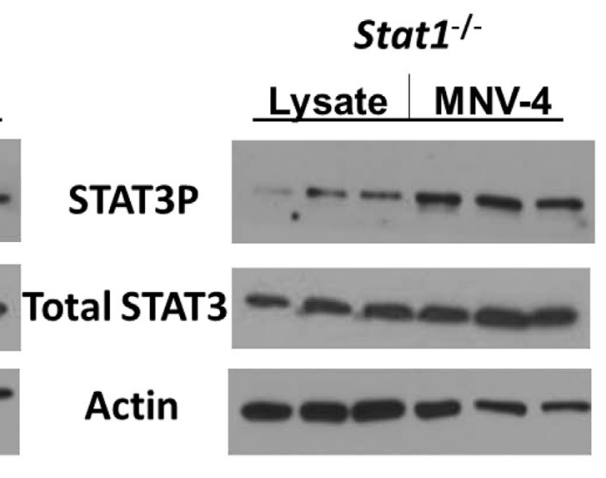

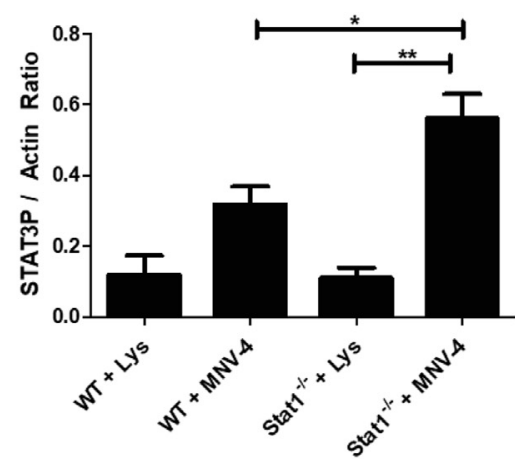

Stat1-/-

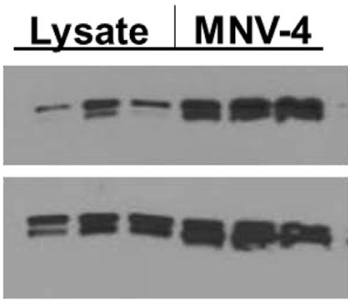

Actin

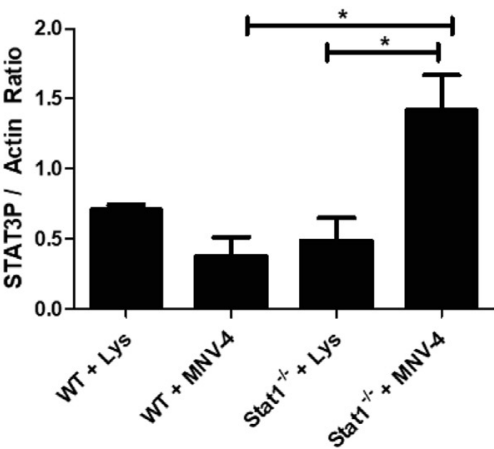

Figure 8 STAT3 phosphorylation in mesenteric lymph node (MLN) and bone marrow of MNV-4-infected mice. Protein lysates were prepared from cell suspensions generated from MLN and bone marrow of Stat $1^{-/-}$mice gavaged with either control lysate (Lys) or MNV- 4 and collected at 7 days p.i. Western blots for STAT3 phosphorylation (STAT3-P), total STAT3, and $\beta$-actin are shown in MLN (A) and bone marrow (B) for one of the three experiments. Signals were quantified from gel images with ImageJ (bar graphs). Data are expressed as means $\pm \operatorname{SEM}(\mathbf{A}$ and $\mathbf{B}) .{ }^{*} P<0.05,{ }^{*} P<0.01$ (two-tailed unpaired $t$-test). WT, wild type.

interpret how expression changes in factors that modify lymphatic behavior are affecting the IBD patient at specific time points. Considering all of these factors, these data suggest a role for lymphatic dysfunction preceding large intestinal inflammation, as has been shown to occur with experimental impairment of lymphatics leading to inflammation and tissue damage. ${ }^{70-72}$

\section{Role of Virus-Induced Lymphatic Abnormalities in IBD}

Our model differs from those recently used to study the role of lymphatic function in intestinal inflammation in that disease is triggered by infection with a virus in an immune-deficient host rather than spontaneously developing or being triggered by a chemical insult. ${ }^{9,50,65}$ Therefore, this model may be useful to understand the potential role of an infectious enteric virus combined with a genetic susceptibility, resulting in Crohn-like changes in the lymphatics. Although evidence supporting a definitive role for viruses in the initiation and progression of human IBD remains elusive, ${ }^{73}$ there is some support for the idea. ${ }^{17,74}$ In addition, there are other examples of viral-induced lymphatic abnormalities that behave not unlike those observed in CD patients. ${ }^{6,75}$ Regarding MNV infection specifically, MNV-4 exacerbates the onset and severity of typhlocolitis in a bacterial-driven model of IBD in $M d r l a^{-1-}$ mice, and this was associated with more severe lesions in the draining lymphatics (such as lymphangitis). ${ }^{22}$ It is unclear whether the lymphatic and other lesions noted in MNV-4-infected Stat ${ }^{-1-}$ mice reflect a direct response to the chronic viral infection at the site of lesion development or an indirect effect resulting from dissemination of inflammatory mediators skewed toward STAT3 signaling, inducing dysregulated lymphatic drainage and/or immune responses. To help answer this question, it would be useful to temporally localize the virus in vivo, during different phases of pathogenesis.

Possible Mechanisms for Lymphatic Pathogenesis in MNV-4-Infected Stat1 ${ }^{-/-}$Mice

\section{Role of Inflammatory Mediators}

Because IFN- $\gamma$ was strongly up-regulated in tissues and serum of MNV-4-infected Stat1 ${ }^{-1-}$ mice early in infection, was sustained through the time points examined, and has been shown to influence lymphatic endothelial cell function, ${ }^{76}$ we hypothesized that STAT1-independent IFN- $\gamma$ responses were important in pathogenesis. However, the experiment in Ifn $\alpha \beta \gamma r^{-/-}$mice, where MNV4-induced disease was not observed, indicates that blocking canonical IFN signaling in the presence of STAT1 is not sufficient to induce lesion development. Furthermore, Stat 1 -independent IFN- $\gamma$ signaling may be protective in these mice, a notion supported by the results 
where treatment of Stat1 $^{-1-}$ mice with anti-IFN- $\gamma$ antibodies before and during the disease development increased lesion severity in MLNs and spleen.

Increased expression of Tnf $\alpha$ and $i N o s$ was also observed in ceca of MNV-4-infected Stat ${ }^{-/-}$mice. TNF- $\alpha$ has been shown to decrease lymphatic pumping by induction of iNOS $^{77}$; however, anti-TNF- $\alpha$ treatment did not attenuate lesions in MNV-4-infected Stat1 ${ }^{-/-}$mice. Nitric oxide has a role in lymphatic flow, and its normal role in lymphatic function can be overwhelmed by production of nitric oxide from inflammatory cells expressing iNOS. ${ }^{78}$ Increased iNos expression and activity has been associated with decreased lymphatic function in several animal models, including one 2,4,6-trinitrobenzene sulfonic acid ileitis induced in guinea pigs. ${ }^{11}$ Although lymphangiectasia was observed in our model, it is unclear if and to what extent lymphodilation contributes to loss of lymphatic function. Furthermore, whether iNOS plays a significant role in our model needs further exploration because there are multiple STAT1independent pathways by which iNos can be up-regulated and it is unclear which are at play in these Stat $^{-1-}$ mice.

\section{Altered STAT Signaling}

From the MLN array data, it appears that STAT3 signaling is increased in MNV-4-infected Stat1 ${ }^{-1-}$ mice. Many STAT3-associated mediators have been linked to altered lymphatic function and are also associated with myeloid cells, which are significantly increased in MNV-4-infected Stat ${ }^{-1-}$ mice. Granulocyte colony-stimulating factor (serum), a major regulator of neutrophil maturation and mobilizer of immature DCs, ${ }^{79}$ as well as the high-affinity $\gamma$ receptor $(F \operatorname{crl} 1 / \mathrm{Cd} 64)$ are both linked to altered STAT3 function. ${ }^{57,80} \mathrm{Lrg}$ expression, also associated with neutrophil function ${ }^{54}$ and endothelial cell function in lymphocyte homing and neovascularization, ${ }^{81}$ is significantly elevated in our model and can increase granulocyte colony-stimulating factor activity via enhanced STAT3 phosphorylation. ${ }^{82}$ STAT3-induced Cepbd expression has specifically been associated with VEGF-C function in lymphangiogenesis. ${ }^{83}$ Together, these data suggest that mobilization and activation of myeloid cell subsets and their inflammatory products early in infection interact with STAT3 phosphorylation through granulocyte colony-stimulating factor signaling, potentially accounting for lymphatic changes. However, it is still unclear to what extent increased phosphorylation of STAT3 and its downstream gene targets are responsible for MNV-4-induced disease in our model. Further study would be needed to determine which cell types and STATsignaling pathways are involved in MNV-4-induced disease in Stat $^{-1-}$ mice. These observations of increased STAT3 function in response to MNV-4 infection may be relevant to human IBD. Lovato et $\mathrm{al}^{84}$ described constitutive phosphorylation of STAT3 in intestinal T cells in CD patients. Furthermore, increased STAT3 activity ${ }^{85}$ has been associated with human autoimmune diseases, which share some features with IBD. ${ }^{86}$

\section{Conclusion}

The presented data demonstrate an interplay between an enteric virus and a genetic susceptibility that has been linked to IBD, which provokes lymphatic changes and eventual development of colitis. MNV-4-infected Stat ${ }^{-1-}$ mice may be a useful animal model to understand mechanisms driving the earliest stages of $\mathrm{CD}$ that cannot be easily studied in humans.

\section{Acknowledgments}

We thank Monica M. McNeal (Cincinnati Children's Hospital Medical Center) for supplying the rhesus rotavirus (RRV), MA-104 cells, and rabbit anti-rotavirus antibody, Dr. Michael Gale (University of Washington, Seattle, WA) for AG129 transgenic mice, Karina Diaz for performing the neutralizing antibody assay for RRV, Olesya Pershutkina for animal care and experimental support, and Denny Liggitt for critical review of our manuscript.

L.M.P. is the guarantor of this work and, as such, had full access to all of the data in the study and takes responsibility for the integrity of the data and the accuracy of the data analysis.

\section{Supplemental Data}

Supplemental material for this article can be found at https://doi.org/10.1016/j.ajpath.2018.03.019.

\section{References}

1. Crohn BB, Ginzburg L, Oppenheimer GD: Regional ileitis a pathologic and clinical entity. J Am Med Assoc 1932, 99:1323-1329

2. Warren S, Sommers SC: Cicatrizing enteritis as a pathologic entity: analysis of 120 cases. Am J Pathol 1948, 24:475-501

3. Lockhart-Mummery HE, Morson BC: Crohn's disease of the large intestine. Gut 1964, 5:493-509

4. Becker F, Potepalov S, Shehzahdi R, Bernas M, Witte M, Abreo F, Traylor J, Orr WA, Tsunoda I, Alexander JS: Downregulation of FoxC2 increased susceptibility to experimental colitis: influence of lymphatic drainage function? Inflamm Bowel Dis 2015, 21: 1282-1296

5. Alexander JS, Chaitanya GV, Grisham MB, Boktor M: Emerging roles of lymphatics in inflammatory bowel disease. Ann N Y Acad Sci 2010, 1207 Suppl 1:E75-E85

6. Van Kruiningen HJ, Colombel JF: The forgotten role of lymphangitis in Crohn's disease. Gut 2008, 57:1-4

7. von der Weid PY, Rehal S, Ferraz JG: Role of the lymphatic system in the pathogenesis of Crohn's disease. Curr Opin Gastroenterol 2011, 27:335-341

8. Sura R, Colombel JF, Van Kruiningen HJ: Lymphatics, tertiary lymphoid organs and the granulomas of Crohn's disease: an immunohistochemical study. Aliment Pharmacol Ther 2011, 33:930-939

9. Cromer W, Wang W, Zawieja SD, von der Weid PY, NewellRogers MK, Zawieja DC: Colonic insult impairs lymph flow, increases cellular content of the lymph, alters local lymphatic microenvironment, and leads to sustained inflammation in the rat ileum. Inflamm Bowel Dis 2015, 21:1553-1563 
10. Van Kruiningen HJ: An infectious pig model of Crohn's disease. Inflamm Bowel Dis 2016, 22:2106-2111

11. Wu TF, Carati CJ, Macnaughton WK, von der Weid PY: Contractile activity of lymphatic vessels is altered in the TNBS model of guinea pig ileitis. Am J Physiol Gastrointest Liver Physiol 2006, 291: G566-G574

12. Sartor RB, Wu GD: Roles for intestinal bacteria, viruses, and fungi in pathogenesis of inflammatory bowel diseases and therapeutic approaches. Gastroenterology 2016, 152:327-339.e4

13. Bosca-Watts MM, Tosca J, Anton R, Mora M, Minguez M, Mora F: Pathogenesis of Crohn's disease: bug or no bug. World J Gastrointest Pathophysiol 2015, 6:1-12

14. Bernstein CN, Blanchard JF: Viruses and inflammatory bowel disease: is there evidence for a causal association? Inflamm Bowel Dis 2000, 6:34-39

15. Wang W, Jovel J, Halloran B, Wine E, Patterson J, Ford G, O'Keefe S, Meng B, Song D, Zhang Y, Tian Z, Wasilenko ST, Rahbari M, Reza S, Mitchell T, Jordan T, Carpenter E, Madsen K, Fedorak R, Dielemann LA, Ka-Shu Wong G, Mason AL: Metagenomic analysis of microbiome in colon tissue from subjects with inflammatory bowel diseases reveals interplay of viruses and bacteria. Inflamm Bowel Dis 2015, 21:1419-1427

16. Khan RR, Lawson AD, Minnich LL, Martin K, Nasir A, Emmett MK, Welch CA, Udall JN Jr: Gastrointestinal norovirus infection associated with exacerbation of inflammatory bowel disease. J Pediatr Gastroenterol Nutr 2009, 48:328-333

17. Lopetuso LR, Ianiro G, Scaldaferri F, Cammarota G, Gasbarrini A: Gut virome and inflammatory bowel disease. Inflamm Bowel Dis 2016, 22:1708-1712

18. Lopman BA, Steele D, Kirkwood CD, Parashar UD: The vast and varied global burden of norovirus: prospects for prevention and control. PLoS Med 2016, 13:e1001999

19. Hsu CC, Piotrowski SL, Meeker SM, Smith KD, Maggio-Price L, Treuting PM: Histologic lesions induced by murine norovirus infection in laboratory mice. Vet Pathol 2016, 53:754-763

20. Karst SM, Wobus CE, Lay M, Davidson J, Virgin HW 4th: STAT1dependent innate immunity to a Norwalk-like virus. Science 2003 , 299:1575-1578

21. Hsu CC, Riley LK, Wills HM, Livingston RS: Persistent infection with and serologic cross-reactivity of three novel murine noroviruses. Comp Med 2006, 56:247-251

22. Lencioni KC, Seamons A, Treuting PM, Maggio-Price L, Brabb T: Murine norovirus: an intercurrent variable in a mouse model of bacteria-induced inflammatory bowel disease. Comp Med 2008, 58: $522-533$

23. Hsu CC, Paik J, Treuting PM, Seamons A, Meeker SM, Brabb TL, Maggio-Price L: Infection with murine norovirus 4 does not alter Helicobacter-induced inflammatory bowel disease in Il10(-/-) mice. Comp Med 2014, 64:256-263

24. Paik J, Fierce Y, Mai PO, Phelps SR, McDonald T, Treuting P, Drivdahl R, Brabb T, LeBoeuf R, O'Brien KD, Maggio-Price L: Murine norovirus increases atherosclerotic lesion size and macrophages in Ldlr(-/-) mice. Comp Med 2011, 61:330-338

25. Basic M, Keubler LM, Buettner M, Achard M, Breves G, Schroder B, Smoczek A, Jorns A, Wedekind D, Zschemisch NH, Gunther C, Neumann D, Lienenklaus S, Weiss S, Hornef MW, Mahler M, Bleich A: Norovirus triggered microbiota-driven mucosal inflammation in interleukin 10-deficient mice. Inflamm Bowel Dis 2014, 20: 431-443

26. Li Y, Zhu W, Zuo L, Shen B: The role of the mesentery in Crohn's disease: the contributions of nerves, vessels, lymphatics, and fat to the pathogenesis and disease course. Inflamm Bowel Dis 2016, 22: $1483-1495$

27. Nieminen JK, Niemi M, Sipponen T, Salo HM, Klemetti P, Farkkila M, Vakkila J, Vaarala O: Dendritic cells from Crohn's disease patients show aberrant STAT1 and STAT3 signaling. PLoS One 2013, 8:e70738
28. Li J, Wei Z, Chang X, Cardinale CJ, Kim CE, Baldassano RN, Hakonarson H; International IBD Genetics Consortium: Pathwaybased genome-wide association studies reveal the association between growth factor activity and inflammatory bowel disease. Inflamm Bowel Dis 2016, 22:1540-1551

29. Norman JM, Handley SA, Baldridge MT, Droit L, Liu CY, Keller BC, Kambal A, Monaco CL, Zhao G, Fleshner P, Stappenbeck TS, McGovern DP, Keshavarzian A, Mutlu EA, Sauk J, Gevers D, Xavier RJ, Wang D, Parkes M, Virgin HW: Diseasespecific alterations in the enteric virome in inflammatory bowel disease. Cell 2015, 160:447-460

30. van den Broek MF, Muller U, Huang S, Aguet M, Zinkernagel RM: Antiviral defense in mice lacking both alpha/beta and gamma interferon receptors. J Virol 1995, 69:4792-4796

31. Hsu CC, Paik J, Brabb TL, O'Brien KD, Kim J, Sullivan BG, Hudkins KL, Seamons A, Finley JC, Meeker SM, Maggio-Price L: Murine norovirus infection variably alters atherosclerosis in mice lacking apolipoprotein E. Comp Med 2015, 65:369-381

32. Hsu CC, Wobus CE, Steffen EK, Riley LK, Livingston RS: Development of a microsphere-based serologic multiplexed fluorescent immunoassay and a reverse transcriptase PCR assay to detect murine norovirus 1 infection in mice. Clin Diagn Lab Immunol 2005, 12 : $1145-1151$

33. Banerji S, Ni J, Wang SX, Clasper S, Su J, Tammi R, Jones M, Jackson DG: LYVE-1, a new homologue of the CD44 glycoprotein, is a lymph-specific receptor for hyaluronan. J Cell Biol 1999, 144: 789-801

34. Ericsson AC, Myles M, Davis W, Ma L, Lewis M, Maggio-Price L, Franklin C: Noninvasive detection of inflammation-associated colon cancer in a mouse model. Neoplasia 2010, 12:1054-1065

35. Abe K, Nguyen KP, Fine SD, Mo JH, Shen C, Shenouda S, Corr M, Jung S, Lee J, Eckmann L, Raz E: Conventional dendritic cells regulate the outcome of colonic inflammation independently of $\mathrm{T}$ cells. Proc Natl Acad Sci U S A 2007, 104:17022-17027

36. Weiss G, Christensen HR, Zeuthen LH, Vogensen FK, Jakobsen M, Frokiaer $\mathrm{H}$ : Lactobacilli and bifidobacteria induce differential interferon-beta profiles in dendritic cells. Cytokine 2011, 56:520-530

37. Zhang Q, Lu Y, Proulx ST, Guo R, Yao Z, Schwarz EM, Boyce BF, Xing L: Increased lymphangiogenesis in joints of mice with inflammatory arthritis. Arthritis Res Ther 2007, 9:R118

38. Hall KL, Volk-Draper LD, Flister MJ, Ran S: New model of macrophage acquisition of the lymphatic endothelial phenotype. PLoS One 2012, 7:e31794

39. Smither SJ, Lear-Rooney C, Biggins J, Pettitt J, Lever MS, Olinger GG Jr: Comparison of the plaque assay and 50\% tissue culture infectious dose assay as methods for measuring filovirus infectivity. J Virol Methods 2013, 193:565-571

40. Hwang S, Alhatlani B, Arias A, Caddy SL, Christodoulou C, Cunha JB, Emmott E, Gonzalez-Hernandez M, Kolawole A, Lu J, Rippinger C, Sorgeloos F, Thorne L, Vashist S, Goodfellow I, Wobus CE: Murine norovirus: propagation, quantification, and genetic manipulation. Curr Protoc Microbiol 2014, 33. 15K.2.1-15K. 2.61

41. McNeal MM, Broome RL, Ward RL: Active immunity against rotavirus infection in mice is correlated with viral replication and titers of serum rotavirus IgA following vaccination. Virology 1994, 204:642-650

42. Gounder AP, Myers ND, Treuting PM, Bromme BA, Wilson SS, Wiens ME, Lu W, Ouellette AJ, Spindler KR, Parks WC, Smith JG: Defensins potentiate a neutralizing antibody response to enteric viral infection. PLoS Pathog 2016, 12:e1005474

43. Ericsson AC, Davis JW, Spollen W, Bivens N, Givan S, Hagan CE, McIntosh M, Franklin CL: Effects of vendor and genetic background on the composition of the fecal microbiota of inbred mice. PLoS One 2015, 10:e0116704

44. Paik J, Kwok F, Seamons A, Brabb T, Kim J, Sullivan B, Hsu C, O'Brien KD, Maggio-Price L: Effects of murine norovirus on 
atherosclerosis in $\operatorname{ldl}(-/ /-)$ mice depends on the timing of infection Comp Med 2015, 65:114-122

45. Paik J, Pershutkina O, Meeker S, Yi JJ, Dowling S, Hsu C, Hajjar AM, Maggio-Price L, Beck DA: Potential for using a hermetically-sealed, positive-pressured isocage system for studies involving germ-free mice outside a flexible-film isolator. Gut Microbes 2015, 6:255-265

46. Hanada T, Kobayashi T, Chinen T, Saeki K, Takaki H, Koga K, Minoda Y, Sanada T, Yoshioka T, Mimata H, Kato S, Yoshimura A: IFNgamma-dependent, spontaneous development of colorectal carcinomas in SOCS1-deficient mice. J Exp Med 2006, 203:1391-1397

47. Lindebo Holm T, Poulsen SS, Markholst H, Reedtz-Runge S: Pharmacological evaluation of the SCID T cell transfer model of colitis: as a model of Crohn's disease. Int J Inflam 2012, 2012:412178

48. Meeker S, Seamons A, Paik J, Treuting PM, Brabb T, Grady WM, Maggio-Price L: Increased dietary vitamin D suppresses MAPK signaling, colitis, and colon cancer. Cancer Res 2014, 74:4398-4408

49. Schneider CA, Rasband WS, Eliceiri KW: NIH Image to ImageJ: 25 years of image analysis. Nat Methods 2012, 9:671-675

50. D'Alessio S, Correale C, Tacconi C, Gandelli A, Pietrogrande G, Vetrano S, Genua M, Arena V, Spinelli A, Peyrin-Biroulet L, Fiocchi C, Danese S: VEGF-C-dependent stimulation of lymphatic function ameliorates experimental inflammatory bowel disease. J Clin Invest 2014, 124:3863-3878

51. Becker F, Yi P, Al-Kofahi M, Ganta VC, Morris J, Alexander JS: Lymphatic dysregulation in intestinal inflammation: new insights into inflammatory bowel disease pathomechanisms. Lymphology 2014, 47:3-27

52. Neurath MF: Cytokines in inflammatory bowel disease. Nat Rev Immunol 2014, 14:329-342

53. Kallal LE, Biron CA: Changing partners at the dance: variations in STAT concentrations for shaping cytokine function and immune responses to viral infections. JAKSTAT 2013, 2:e23504

54. O'Donnell LC, Druhan LJ, Avalos BR: Molecular characterization and expression analysis of leucine-rich alpha2-glycoprotein, a novel marker of granulocytic differentiation. J Leukoc Biol 2002, 72: $478-485$

55. Yan C, Liu Y, Gao H, Wang X: Suppressors of cytokine signaling 3 is essential for FcgammaR-mediated inflammatory response via enhancing CCAAT/enhancer-binding protein delta transcriptional activity in macrophages. Exp Cell Res 2015, 337:120-127

56. Tillinger W, Jilch R, Jilma B, Brunner H, Koeller U, Lichtenberger C, Waldhor T, Reinisch W: Expression of the high-affinity IgG receptor FcRI (CD64) in patients with inflammatory bowel disease: a new biomarker for gastroenterologic diagnostics. Am J Gastroenterol 2009, 104:102-109

57. Bovolenta C, Gasperini S, Cassatella MA: Granulocyte colonystimulating factor induces the binding of STAT1 and STAT3 to the IFNgamma response region within the promoter of the $\mathrm{Fc}$ (gamma) RI/CD64 gene in human neutrophils. FEBS Lett 1996, 386:239-242

58. Hsu CC, Meeker SM, Escobar S, Brabb TL, Paik J, Park H, Iritani BM, Maggio-Price L: Murine norovirus inhibits B cell development in the bone marrow of STAT1-deficient mice. Virology 2018, 515:123-133

59. Shortland A, Chettle J, Archer J, Wood K, Bailey D, Goodfellow I, Blacklaws BA, Heeney JL: Pathology caused by persistent murine norovirus infection. J Gen Virol 2014, 95:413-422

60. Geleff S, Schoppmann SF, Oberhuber G: Increase in podoplaninexpressing intestinal lymphatic vessels in inflammatory bowel disease. Virchows Arch 2003, 442:231-237

61. Rahier JF, De Beauce S, Dubuquoy L, Erdual E, Colombel JF, JouretMourin A, Geboes K, Desreumaux P: Increased lymphatic vessel density and lymphangiogenesis in inflammatory bowel disease. Aliment Pharmacol Ther 2011, 34:533-543

62. Bressenot A, Peyrin-Biroulet L: Histologic features predicting postoperative Crohn's disease recurrence. Inflamm Bowel Dis 2015, 21 : $468-475$
63. Randolph GJ, Bala S, Rahier JF, Johnson MW, Wang PL, Nalbantoglu I, Dubuquoy L, Chau A, Pariente B, Kartheuser A, Zinselmeyer BH, Colombel JF: Lymphoid aggregates remodel lymphatic collecting vessels that serve mesenteric lymph nodes in Crohn disease. Am J Pathol 2016, 186:3066-3073

64. Jurisic G, Sundberg JP, Bleich A, Leiter EH, Broman KW, Buechler G, Alley L, Vestweber D, Detmar M: Quantitative lymphatic vessel trait analysis suggests Vcam1 as candidate modifier gene of inflammatory bowel disease. Genes Immun 2010, 11: 219-231

65. Jurisic G, Sundberg JP, Detmar M: Blockade of VEGF receptor-3 aggravates inflammatory bowel disease and lymphatic vessel enlargement. Inflamm Bowel Dis 2013, 19:1983-1989

66. Wang XL, Zhao J, Qin L, Qiao M: Promoting inflammatory lymphangiogenesis by vascular endothelial growth factor-C (VEGF-C) aggravated intestinal inflammation in mice with experimental acute colitis. Braz J Med Biol Res 2016, 49:e4738

67. Pedica F, Ligorio C, Tonelli P, Bartolini S, Baccarini P: Lymphangiogenesis in Crohn's disease: an immunohistochemical study using monoclonal antibody D2-40. Virchows Arch 2008, 452:57-63

68. Algaba A, Linares PM, Fernandez-Contreras ME, Ordonez A, Trapaga J, Guerra I, Chaparro M, de la Poza G, Gisbert JP, Bermejo F: Relationship between levels of angiogenic and lymphangiogenic factors and the endoscopic, histological and clinical activity, and acute-phase reactants in patients with inflammatory bowel disease. J Crohns Colitis 2013, 7:e569-e579

69. Tonelli F, Giudici F, Liscia G: Is lymphatic status related to regression of inflammation in Crohn's disease? World J Gastrointest Surg 2012, 4:228-233

70. Chess S, Chess D, Olander G, Benner W, Cole WH: Production of chronic enteritis and other systemic lesions by ingestion of finely divided foreign materials. Surgery 1950, 27:220-234

71. Kalima TV: Experimental lymphatic obstruction in the ileum. Ann Chir Gynaecol Fenn 1970, 59:187-201

72. Kalima TV, Saloniemi H, Rahko T: Experimental regional enteritis in pigs. Scand J Gastroenterol 1976, 11:353-362

73. Masclee GM, Penders J, Pierik M, Wolffs P, Jonkers D: Enteropathogenic viruses: triggers for exacerbation in IBD? a prospective cohort study using real-time quantitative polymerase chain reaction. Inflamm Bowel Dis 2013, 19:124-131

74. Hubbard VM, Cadwell K: Viruses, autophagy genes, and Crohn's disease. Viruses 2011, 3:1281-1311

75. Van Kruiningen HJ: Missing the target to treat in Crohn's disease. Clin Gastroenterol Hepatol 2015, 13:2381-2382

76. Cromer WE, Zawieja SD, Tharakan B, Childs EW, Newell MK, Zawieja DC: The effects of inflammatory cytokines on lymphatic endothelial barrier function. Angiogenesis 2014, 17:395-406

77. Chen Y, Rehal S, Roizes S, Zhu HL, Cole WC, von der Weid PY: The pro-inflammatory cytokine TNF-alpha inhibits lymphatic pumping via activation of the NF-kappaB-iNOS signaling pathway. Microcirculation 2017, 24:e12364

78. Kesler CT, Liao S, Munn LL, Padera TP: Lymphatic vessels in health and disease. Wiley Interdiscip Rev Syst Biol Med 2013, 5:111-124

79. Rutella S, Zavala F, Danese S, Kared H, Leone G: Granulocyte colony-stimulating factor: a novel mediator of $\mathrm{T}$ cell tolerance. $\mathrm{J}$ Immunol 2005, 175:7085-7091

80. Kamezaki K, Shimoda K, Numata A, Haro T, Kakumitsu H, Yoshie M, Yamamoto M, Takeda K, Matsuda T, Akira S, Ogawa K, Harada M: Roles of Stat3 and ERK in G-CSF signaling. Stem Cells 2005, 23:252-263

81. Lee M, Kiefel H, LaJevic MD, Macauley MS, Kawashima H, O’Hara E, Pan J, Paulson JC, Butcher EC: Transcriptional programs of lymphoid tissue capillary and high endothelium reveal control mechanisms for lymphocyte homing. Nat Immunol 2014, 15: 982-995

82. Ai J, Druhan LJ, Hunter MG, Loveland MJ, Avalos BR: LRGaccelerated differentiation defines unique G-CSFR signaling 
pathways downstream of PU.1 and C/EBPepsilon that modulate neutrophil activation. J Leukoc Biol 2008, 83:1277-1285

83. Min Y, Ghose S, Boelte K, Li J, Yang L, Lin PC: C/EBP-delta regulates VEGF-C autocrine signaling in lymphangiogenesis and metastasis of lung cancer through HIF-1alpha. Oncogene 2011, 30: 4901-4909

84. Lovato P, Brender C, Agnholt J, Kelsen J, Kaltoft K, Svejgaard A, Eriksen KW, Woetmann A, Odum N: Constitutive STAT3 activation in intestinal T cells from patients with Crohn's disease. J Biol Chem 2003, 278:16777-16781

85. Milner JD, Vogel TP, Forbes L, Ma CA, Stray-Pedersen A, Niemela JE, et al: Early-onset lymphoproliferation and autoimmunity caused by germline STAT3 gain-of-function mutations. Blood 2015, 125:591-599

86. Wen Z, Fiocchi C: Inflammatory bowel disease: autoimmune or immune-mediated pathogenesis? Clin Dev Immunol 2004, 11:195-204 